\title{
A conserved MADS-box phosphorylation motif regulates differentiation and mitochondrial function in skeletal, cardiac, and smooth muscle cells
}

\author{
W Mughal ${ }^{1,2}$, L Nguyen ${ }^{2}$, S Pustylnik ${ }^{3}$, SC da Silva Rosa ${ }^{1,2}$, S Piotrowski $^{1,2}$, D Chapman ${ }^{2,4}$, M Dü $^{3}$, NS Alli ${ }^{3}$, J Grigull ${ }^{3,5}$, AJ Halayko $0^{6,7}$, \\ M Aliani $^{8}$, MK Topham 9 , RM Epand ${ }^{10}$, GM Hatch ${ }^{2,11}$, TJ Pereira ${ }^{2,11}$, S Kereliuk ${ }^{2,11}$, JC McDermott ${ }^{3}$, C Rampitsch ${ }^{12}$, VW Dolinsky ${ }^{2,11}$ \\ and JW Gordon ${ }^{\star, 1,2,4}$
}

Exposure to metabolic disease during fetal development alters cellular differentiation and perturbs metabolic homeostasis, but the underlying molecular regulators of this phenomenon in muscle cells are not completely understood. To address this, we undertook a computational approach to identify cooperating partners of the myocyte enhancer factor-2 (MEF2) family of transcription factors, known regulators of muscle differentiation and metabolic function. We demonstrate that MEF2 and the serum response factor (SRF) collaboratively regulate the expression of numerous muscle-specific genes, including microRNA-133a (miR-133a). Using tandem mass spectrometry techniques, we identify a conserved phosphorylation motif within the MEF2 and SRF Mcm1 Agamous Deficiens SRF (MADS)-box that regulates miR-133a expression and mitochondrial function in response to a lipotoxic signal. Furthermore, reconstitution of MEF2 function by expression of a neutralizing mutation in this identified phosphorylation motif restores miR-133a expression and mitochondrial membrane potential during lipotoxicity. Mechanistically, we demonstrate that miR-133a regulates mitochondrial function through translational inhibition of a mitophagy and cell death modulating protein, called Nix. Finally, we show that rodents exposed to gestational diabetes during fetal development display muscle diacylglycerol accumulation, concurrent with insulin resistance, reduced miR-133a, and elevated Nix expression, as young adult rats. Given the diverse roles of miR-133a and Nix in regulating mitochondrial function, and proliferation in certain cancers, dysregulation of this genetic pathway may have broad implications involving insulin resistance, cardiovascular disease, and cancer biology.

Cell Death and Disease (2015) 6, e1944; doi:10.1038/cddis.2015.306; published online 29 October 2015

Extensive cell and molecular analysis has identified numerous extracellular cues that regulate skeletal, cardiac, and smooth muscle myogenesis. ${ }^{1-3}$ However, the impact of nutrient availability and metabolic excess on myogenesis has been less studied. One of the most important periods of myogenesis is during gestation, and fetal exposure to metabolic diseases dramatically alters the development and post-natal metabolism of muscle. For example, the offspring of overweight pregnant rats have reduced muscle fibers and nuclei. ${ }^{4}$ In addition, fetal exposure to diabetes during pregnancy increases the risk for early-onset insulin resistance in the offspring; ${ }^{5}$ however, the key molecular regulators responsible for fetal metabolic programming have not been characterized in muscle tissues.

During mammalian development, myogenic precursors derived mostly from mesenchymal populations commit to one of three main muscle lineages: skeletal, cardiac, and smooth muscles. ${ }^{2,6-8}$ Among the core muscle transcriptional regulators is the myocyte enhancer factor-2 (MEF2) family of transcription factors, where gene-targeting studies in both Drosophila and mammals have reported essential roles for the MEF2 family in the development and post-natal remodeling of all muscle lineages. ${ }^{9}$

The MEF2 family is composed of four transcription factors, MEF2-A to -D, which have both overlapping and nonredundant functions. The amino terminus of MEF2 proteins contains a highly conserved 58-amino acid Mcm1 Agamous Deficiens SRF (MADS)-box that mediates dimerization and binding to a cognate cis element $(\mathrm{T} / \mathrm{C}) \mathrm{TA}(\mathrm{A} / \mathrm{T})_{4} \mathrm{TA}(\mathrm{G} / \mathrm{A}){ }^{10}$ The transcriptional activity of MEF2 proteins, along with their ability to bind DNA, is highly regulated by post-translational modification, including phosphorylation. ${ }^{11-13}$ In mammalian

\footnotetext{
${ }^{1}$ Department of Human Anatomy and Cell Science, University of Manitoba, Winnipeg, MB, Canada; ${ }^{2}$ The Diabetes Research Envisioned and Accomplished in Manitoba (DREAM) Theme of the Children's Hospital Research Institute of Manitoba, University of Manitoba, Winnipeg, MB, Canada; ${ }^{3}$ Department of Biology, York University, Toronto, ON, Canada; ${ }^{4}$ College of Nursing, University of Manitoba, Winnipeg, MB, Canada; ${ }^{5}$ Department of Mathematics and Statistics, York University, Toronto, ON, Canada; ${ }^{6}$ Department of Physiology and Pathophysiology, University of Manitoba, Winnipeg, MB, Canada; ${ }^{7}$ The Biology of Breathing Theme of the Children's Hospital Research Institute of Manitoba, University of Manitoba, Winnipeg, MB, Canada; ${ }^{8}$ Department of Human Nutritional Sciences, University of Manitoba, Winnipeg, MB, Canada; ${ }^{9}$ Huntsman Cancer Institute, University of Utah, Salt Lake City, UT, USA; ${ }^{10}$ Department of Biochemistry and Biomedical Sciences, McMaster University, Hamilton, ON, Canada; ${ }^{11}$ Department of Pharmacology and Therapeutics, University of Manitoba, Winnipeg, MB, Canada and ${ }^{12}$ Agriculture and Agrifood Canada, Morden, MB, Canada ${ }^{*}$ Corresponding author: JW Gordon, Diabetes Research Envisioned and Accomplished in Manitoba (DREAM) Research Group, Department of Human Anatomy and Cell Science, Children's Hospital Research Institute of Manitoba, College of Nursing, Faculty of Health Sciences, University of Manitoba, 715 McDermot Avenue, Winnipeg, MB, Canada R3E 3P4. Tel: +1 204474 6668; Fax: +1 204474 7682; E-mail: joseph.gordon@umanitoba.ca

Abbreviations: MEF2, myocyte enhancer factor-2; SRF, serum response factor; miR-133a, microRNA-133a; MADS domain-box, Mcm1 Agamous Deficiens SRF; PKC $\delta$, protein kinase $\mathrm{C} \delta$; HFS, high-fat and sucrose; Nix/Bnip3L, BCL2/adenovirus E1B 19 kDa protein-interacting protein 3-like; PTP, permeability transition pore; DGK $\delta$, diacylglycerol kinase- $\delta$

Received 22.4.15; revised 07.9.15; accepted 14.9.15; Edited by G Raschellá
} 
cells, the only other MADS-box containing transcription factor is the serum response factor (SRF), which binds to a similar cognate cis element, $\mathrm{CC}(\mathrm{A} / \mathrm{T})_{6} \mathrm{GG},{ }^{14}$ and has also been implicated in smooth muscle and striated muscle differentiation. 3,15,16 Given their similar structure and overlapping function, surprisingly little is known regarding the cooperation between MEF2 and SRF proteins during muscle differentiation, and whether these MADS-box factors serve to coordinate aspects of mitochondrial function.

MEF2 proteins regulate metabolism and muscle fiber-type by direct transcriptional activation of numerous enzymes and transporters important for muscle metabolism, as well as the mitochondrial biogenesis inducer PGC-1a. ${ }^{17}$ Furthermore, MEF2 has been demonstrated to regulate the expression of several microRNA clusters, including microRNA-133a (miR-133a), that operate during muscle differentiation and regulate mitochondrial function. ${ }^{18,19}$ In skeletal muscle, mice harboring deletions in the miR-133a alleles display a severe myopathy, accompanied by impaired mitochondrial respiration. ${ }^{19}$ Furthermore, miR-133a has been shown to regulate smooth muscle phenotype by altering proliferation. ${ }^{20}$

Diacylglycerol levels are chronically elevated in muscle tissues of obese and diabetic rodent models, and contribute to the lipotoxic and insulin-resistant state. ${ }^{21,22}$ Therefore, one possible intracellular signaling pathway linking muscle metabolism with myogenesis is the diacylglycerol-protein kinase $\mathrm{C}$ $(\mathrm{PKC}) \delta$ pathway. This pathway has been implicated in aberrant vascular smooth muscle growth, and can be viewed as an integrator of both metabolic and mitogenic cues. ${ }^{23}$ Interestingly, in human neonatal fibroblasts, PKC $\delta$ can inhibit SRF function by direct phosphorylation of threonine-160, which impairs SRF DNA binding leading to cell senescence. ${ }^{24}$ Furthermore, $\mathrm{PKC} \delta$ signaling is reinforced by the proteolytic cleavage of a small constituently active $\mathrm{PKC} \delta$ catalytic fragment from full-length $\mathrm{PKC} \delta .^{24}$ However, whether this pathway regulates MEF2 or SRF in muscle tissues is untested.

In this report, we present the findings of an unbiased bioinformatics screen, utilizing position weight matrices. This computational approach predicted the co-occurrence of cis elements and a functional interaction between MEF2 and SRF. Experimentally, we demonstrate that MEF2C and SRF cooperatively activate the expression of miR-133a. Furthermore, we identify a conserved MADS-box phosphorylation motif, targeted by $\mathrm{PKC} \delta$, that serves to regulate endogenous miR-133a expression and mitochondrial function in all three muscle lineages. Finally, our data reveal that this signaling module is regulated by lipotoxicity to control mitochondrial function through the regulation of Nix, a known mitophagy and programmed cell death mediator. ${ }^{25}$

\section{Results}

Computational screen to predict transcription factor cooperation during muscle differentiation. To identify factors that collaborate with MEF2 proteins during muscle differentiation, we performed a bioinformatics screen that combined position weight matrices, conservation index, and optimized matrix threshold approaches. Since combinations of transcription factors regulate gene expression through their respective cis elements, this computational approach is founded on the hypothesis that one could predict functionally interacting factors based on the co-occurrence of their cis elements, within evolutionary conserved genomic regions. This analysis revealed that MEF2 is predicted to have target genes in common with seven other transcription factors (Supplementary Table 1). Among these was a predicted functional interaction between MEF2 and SRF. Since both MEF2 and SRF contain MADS-box domains, we investigated the hypothesis that MEF2 and SRF functionally cooperate during muscle differentiation and that this cooperation is regulated by a common intracellular signaling pathway.

MEF2 and SRF cooperatively activate selective musclespecific promoters. To experimentally validate the results of our bioinformatics screen, we initially studied the activation of the muscle creatine kinase (MCK) promoter as an index of muscle gene expression. ${ }^{13}$ We also evaluated representative cardiac (atrial natriuretic factor, ANF) and smooth muscle (telokin) promoters. As predicted by our bioinformatics screen, MEF2A and SRF cooperatively activated these promoters in Cos7 cells (Supplementary Figure 1). Next, we systematically engineered mutations in these promoters in order to understand how preventing MEF2 or SRF binding impacts promoter activity. For these experiments, the promoters were transfected into $\mathrm{C} 2 \mathrm{C} 12$ cells, H9c2 cells, or a senescent-resistant human airway smooth muscle cell line (hASMC) to represent skeletal, cardiac, and smooth muscle myoblasts. Mutation of either the MEF2 or SRF cis element reduced the activity of the MCK, ANF, and telokin promoters (Supplementary Figure 1). Interestingly, mutation of the MEF2 cis element rendered the ANF and telokin reporter genes less responsive to mutation of the SRF site. Furthermore, mutation of all three cis elements simultaneously in the MCK promoter did not reduce promoter activity more than mutation of either MEF2 site alone. Collectively, these observations demonstrate a degree of functional dependency between MEF2 and SRF in the activation of these promoters in three different muscle cell lines.

MEF2C and SRF regulate the endogenous expression of miR-133a. Next, we focused our studies on the endogenous expression of a single MEF2 and SRF target gene that is expressed in all muscle lineages. For this we chose miR-133a, given that it has been recently identified as a regulator of muscle growth and metabolic function. ${ }^{18-20}$ We began with a gain-of-function approach, where $\mathrm{C} 2 \mathrm{C} 12$ myoblasts were transfected with MEF2A, MEF2C, and SRF, alone and in combination. The combination of MEF2C and SRF induced endogenous miR-133a expression in differentiating $\mathrm{C} 2 \mathrm{C} 12$ myotubes (Figure 1a), and we confirmed that ectopic expression of MEF2C and SRF was maintained at this timepoint (Supplementary Figure 2). Importantly, either factor alone had no effect, and MEF2A did not activate miR-133a expression. Interestingly, miR-133a has been shown to target both SRF and MEF2C, which suggests an element of feedback controlling the expression of this microRNA. ${ }^{26,27}$ Next, C2C12 myoblasts were transfected with plasmids encoding short-hairpin RNAs (shRNAs) 
miR-133a qPCR

5 day Differentiation

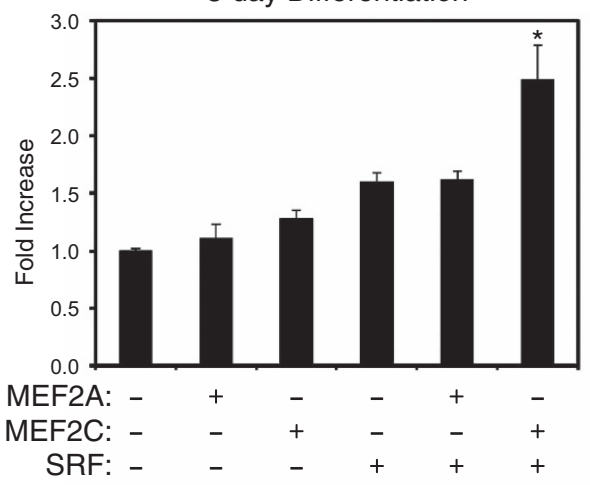

b

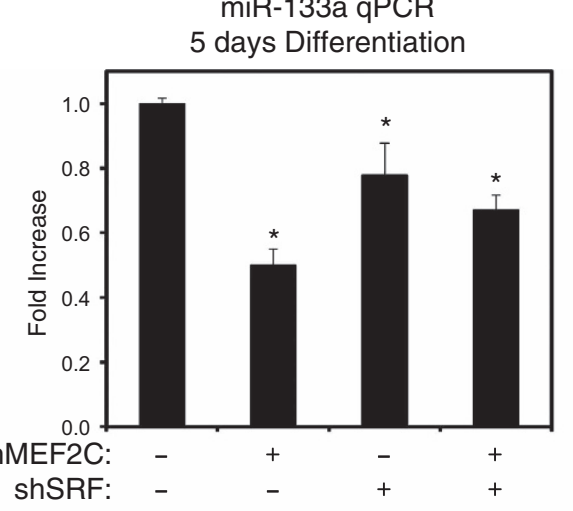

C

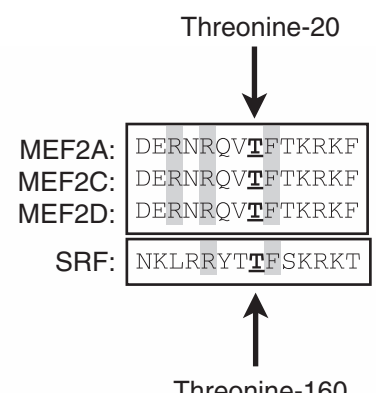

Threonine-160 d

MEF2 aa14-27: ERNRQVTFTKRKFG

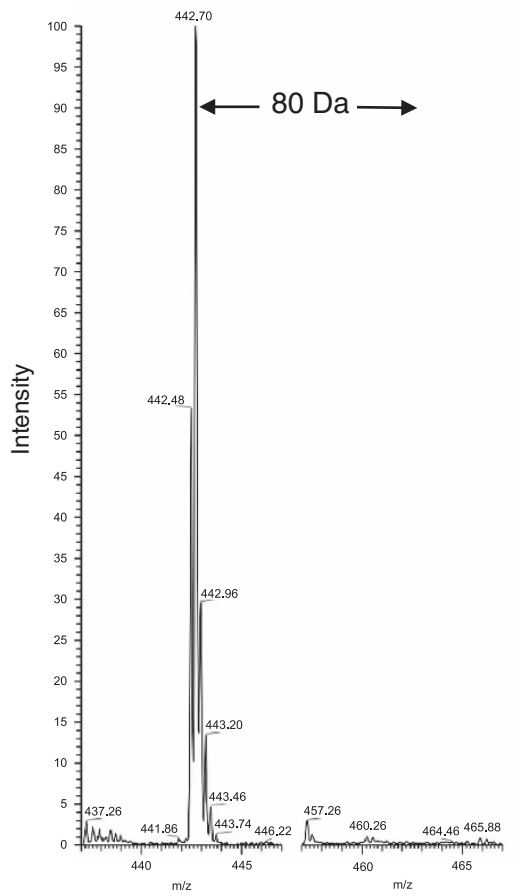

e

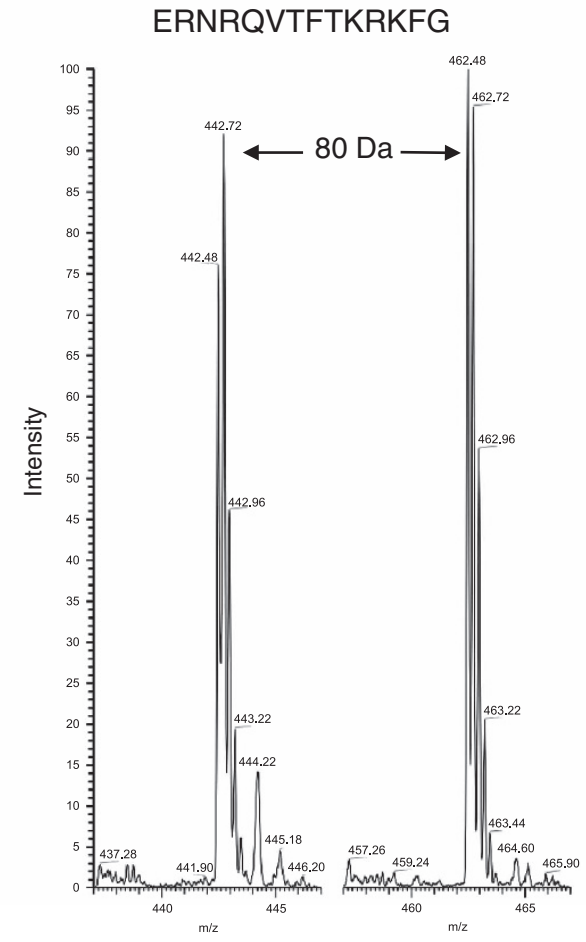

f

MEF2 aa14-27: ERNRQV $\underline{A} F T K R K F G$ 35.00

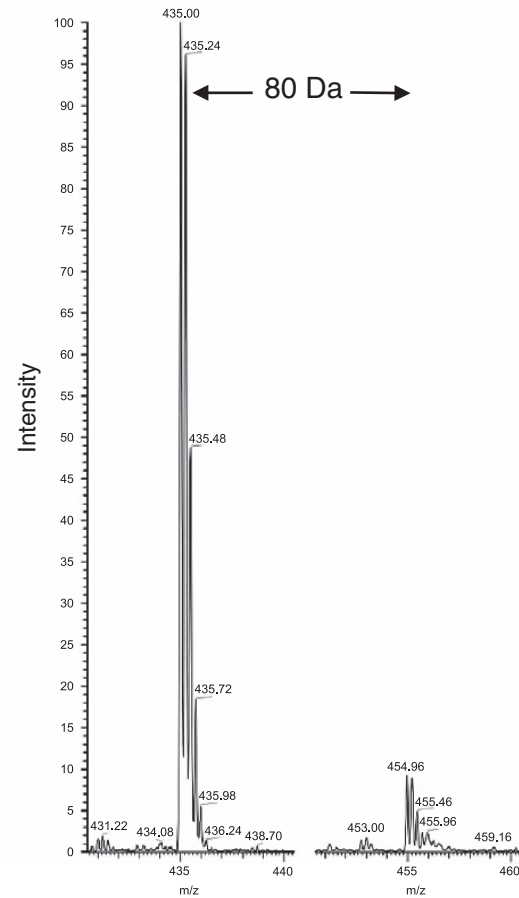

Figure $1 \mathrm{PKC} \delta$ inhibits the cooperation between MEF2 and SRF by direct phosphorylation. (a) C2C12 myoblasts were transfected with MEF2A, MEF2C, or SRF, as indicated. Following recovery, cells were differentiated in low serum media for 5 days and harvested for RNA. Quantitative PCR assays were performed using the $\Delta \Delta C T$ method, where RNU6 was used as an internal control. (b) C2C12 cells were transfected with shRNAs targeting MEF2C (shMEF2C) or SRF (shSRF), as indicated. Following 5 days of differentiation, cells were harvested and assayed as described above. (c) Schematic demonstrating the conservation surrounding the MEF2 threonine-20 and SRF threonine-160 phosphorylation motif. (d-f) SIM scans of the wild-type peptide (d and e) spanning the MADS-box motif of MEF2A. The unphosphorylated peptide (left) has $442 \mathrm{~m} / z$, while the putative phosphorylation (right in b) showing an increased $\mathrm{m} / \mathrm{z}$ of 20 that corresponds to $\mathrm{PO}_{3}(M=80.00 \mathrm{Da}$ ). (f) $\mathrm{A}$ SIM scan of a mutated peptide where threonine-20 is replaced with alanine is shown. On the right, phosphorylation of this mutate peptide is negligible at the predicted $\mathrm{m} / \mathrm{z}$ that corresponds to the addition of a $\mathrm{PO}_{3}(\mathrm{M}=80.00 \mathrm{Da})$. Both peptides are quadruply charged $\left(z=4^{+}\right)$. Data are represented as mean \pm S.E.M. ${ }^{*} P<0.05$ compared with control

targeting MEF2C and SRF. Knockdown of MEF2C or SRF individually reduced the endogenous expression of miR-133a in differentiating myotubes (Figure 1b). Interestingly, simultaneous knockdown of both MEF2C and SRF did not additively reduce miR-133a expression (Figure 1b). Furthermore, knockdown of MEF2C and SRF was confirmed by qPCR at this timepoint (Supplementary Figure 2). These findings suggest a degree of functional dependency between MEF2C and SRF in the regulation of miR-133a expression that is consistent with our promoter analysis in Supplementary Figure 1.

Peptide mapping of PKC $\delta$ phosphorylation of MEF2 and SRF by mass spectrometry. Previously, it was demonstrated that PKC $\delta$ phosphorylates SRF at threonine-160 to inhibit DNA binding. ${ }^{24}$ Since threonine-160 lies within the MADS-box of SRF, we aligned the amino-acid sequence of the MEF2 and SRF MADS-domains and found a high degree 
of conservation surrounding this phosphorylation site (Figure 1c), suggesting that this is a conserved MADS-box phosphorylation motif. To determine whether PKC $\delta$ directly phosphorylates this conserved MADS-box motif in MEF2 proteins, we performed in vitro kinase assays using engineered peptides representing amino acids 14-27 of MEF2. Following exposure to a kinase reaction with purified $\mathrm{PKC} \delta$, peptides were analyzed by mass spectrometry. As shown in Figure 1d, a single ion monitoring (SIM) scan of the the control peptide displayed a predominant peak at $\mathrm{m} / \mathrm{z}$ of $442.74\left(z=4^{+}\right)$; however, following kinase incubation the peptide showed an increased $\mathrm{m} / \mathrm{z}$ of 20 , corresponding to the addition of a phosphate $\left(\mathrm{PO}_{3}\right)$ to the peptide (Mass $=80.00$ $\mathrm{Da}$; Figure 1e). Although an $80-\mathrm{Da}$ mass shift is consistent with phosphorylation, it is neither unequivocal, nor does it permit localization of the phosphorylated amino acid. For location, we engineered an additional peptide where the residue representing threonine-20 was mutated to a neutral alanine. Mutation of threonine-20 substantially reduced the 80-Da mass shift (Figure 1f). These findings support the notion that threonine-20 is phosphorylated by $\mathrm{PKC} \delta$.

Next, we analyzed the $\mathrm{MS}^{2}$ spectra produced by collisioninduced dissociation (CID) of the precursor ion with $m / z=462.98\left(z=4^{+}\right.$; shown in Figure 2a). CID typically fragments phospho-peptides (pS or pT) by breaking the labile O-phosphodiester bond. This results in the neutral loss of $\mathrm{H}_{3} \mathrm{PO}_{4}$, and a prominent neutral loss product-ion dominates the resulting $\mathrm{MS}^{2}$ spectrum. CID of the wild-type phospho-peptide yielded a product-ion with $\mathrm{m} / \mathrm{z}=438.42$ (delta $=24.56$ ), consistent with phosphorylation $(98.0 / 4=24.5$; Figure 4a). Furthermore, the precursor ion $\left(\mathrm{m} / \mathrm{z}=462.98, z=4^{+}\right)$ was selected for electron transfer dissociation (ETD). This technique breaks peptide bonds, but retains side-chain modifications, such as phosphorylation. $\mathrm{MS}^{2}$ spectra following ETD definitively identified threonine-20 of MEF2 as the phosphorylation residue (Figure $2 b$ ). Similar findings were observed for peptides spanning threonine-160 of SRF (Figures 2c-e).

\section{Site-directed mutagenesis of the PKC $\delta$ phospho-} acceptor site on MEF2 and functional analysis. To ascertain the cellular significance of $\mathrm{PKC} \delta$-dependent phosphorylation of threonine-20 of MEF2 and threonine-160 of SRF, we generated neutral alanine (MEF2A-T20A and SRFT160A) and phospho-mimetic aspartic acid (MEF2A-T20D and SRF-T160D) mutations at these residues. As shown in Figure $3 a$, the MEF2A-T20A mutation displayed a modest increase in activity compared with wild-type MEF2A on a concatemerized MEF2-driven promoter (MEF2-luc), while the phospho-mimetic MEF2-T20D mutant provided no activation of this reporter construct. The expression of these mutants was confirmed by western blot to ensure that the introduced mutations did not alter MEF2 stability (Figure 3a). Similar findings were observed using a MCK-GFP reporter gene in differentiating $\mathrm{C} 2 \mathrm{C} 12$ cells (Supplementary Figure 3c). Furthermore, we generated alanine and aspartic acid mutations of threonine-20 in a MEF2-VP16 fusion construct, where the MADS-box and adjacent MEF2 domain (amino acids 1-91 of MEF2A) are fused to the viral VP16 transcriptional activation domain. ${ }^{23,28}$ These expression plasmids demonstrated similar activation pattern in a luciferase assay as the MEF2A mutations (Supplementary Figure 3). Finally, we determined that the phosho-mimetic mutations in MEF2A and SRF could disrupt the functional cooperation between these factors on the telokin promoter (Supplementary Figure 3D).

Next, we evaluated whether the endogenous expression of miR-133a by MEF2C and SRF was regulated by PKC $\delta$. When the catalytic fragment of PKC $\delta$ was co-expressed with MEF2C and SRF, the induction of miR-133a was inhibited in differentiating $\mathrm{C} 2 \mathrm{C} 12 \mathrm{~s}$ (Figure $3 \mathrm{~b}$ ). To determine the effect of an endogenous activator of PKC $\delta$ on miR-133a expression, we exposed cells to the saturated fatty acid palmitate. ${ }^{21}$ This treatment increased the active catalytic fragment of PKC $\delta$ (Figure 3c). Concurrently, we observed reduced expression of miR-133a (Figure 3d). Furthermore, when C2C12 cells were transfected with T20A-VP16, palmitate treatment was unable to inhibit miR-133a expression (Figure 3e).

To further define the role of diacylglycerols and PKC $\delta$ activation in the phosphorylation of the MADS-box motif, we utilized mouse embryonic fibroblasts genetically deficient in diacylglycerol kinase- $\delta(D G K \delta) .{ }^{29}$ These cells display defective lipogenesis and reduced levels of diacylglycerols. ${ }^{29}$ Compared with wild-type cells, DGK $\delta$-null fibroblasts have reduced $\mathrm{PKC} \delta$ activity, determined by expression of the active catalytic fragment, in both vehicle- and palmitate-treated conditions (Figure 3f). Furthermore, we observed that phosphorylation of threonine-160 of SRF is reduced in the DGK $\delta$-null fibroblasts, and that phosphorylation of this site is not enhanced by exposure to palmitate, as it is in wild-type fibroblasts (Figure 3f). These findings strongly implicate de novo diacylglycerol production and subsequent $\mathrm{PKC} \delta$ activation in the phosphorylation of this MADS-box motif.

\section{Palmitate-induced mitochondrial depolarization involves} PKC $\delta$ and inhibition of miR-133a expression. Given the recently described role of $\mathrm{miR}-133 \mathrm{a}$ in regulating muscle mitochondrial respiration, ${ }^{19}$ we hypothesized that palmitateinduced mitochondrial dysfunction involves $\operatorname{PKC} \delta$-dependent miR-133a inhibition. To test this hypothesis, we differentiated C2C12 cells and hASMCs, followed by overnight treatment with palmitate, and stained cells with fluorescent mitochondrial dyes. Palmitate treatment reduced TMRM staining in both cell lines (Figure 4a). Interestingly, palmitate treatment had little effect on MitoView Green staining in $\mathrm{C} 2 \mathrm{C} 12$ myotubes, indicating a loss of mitochondrial membrane potential without a substantial loss of mitochondrial content (Figures $4 \mathrm{a}-\mathrm{C}$ ). However, treatment of $\mathrm{C} 2 \mathrm{C} 12$ cells and hASMCs with the PKC $\delta$ inhibitor rottlerin abrogated the palmitate-induced loss of mitochondrial membrane potential (Figures $4 \mathrm{a}-\mathrm{c}$ ). Correspondingly, palmitate treatment reduced miR-133a expression, which was reversed by PKC $\delta$ inhibition by rottlerin (Figure 4d). Finally, we evaluated MEF2C phosphorylation at threonine-20 by immunoprecipitating endogenous MEF2C and western blotting the eluted proteins with a phospho-specific antibody that recognizes phospho-serines or phospho-threonines with arginine residues at the -3 and -5 positions $(R X R X X p S / T) .{ }^{30}$ As shown in Figure $4 \mathrm{f}$, palmitate exposure increased MEF2C phosphorylation, which was reversed by rottlerin treatment. 
a

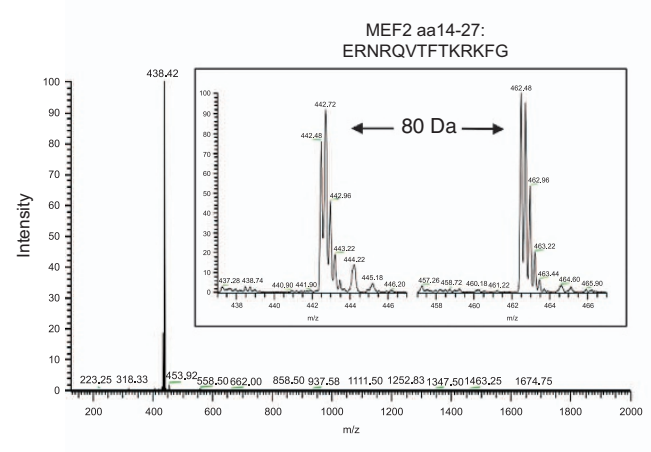

C

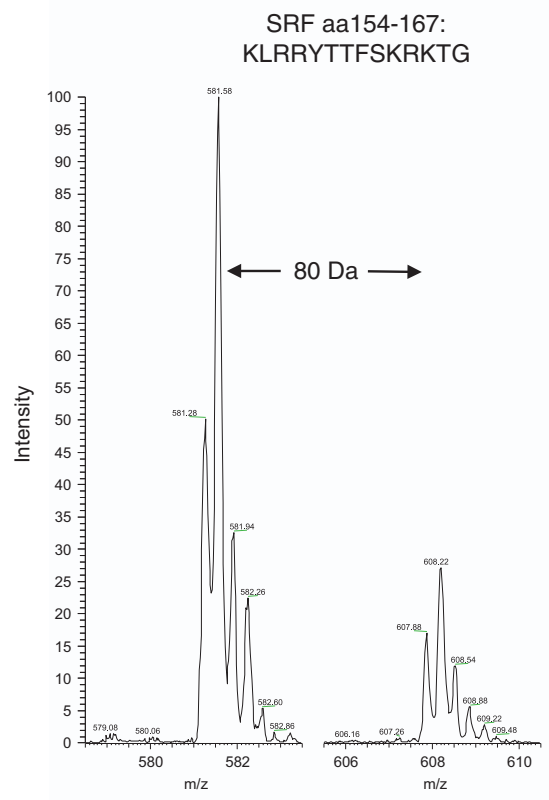

b

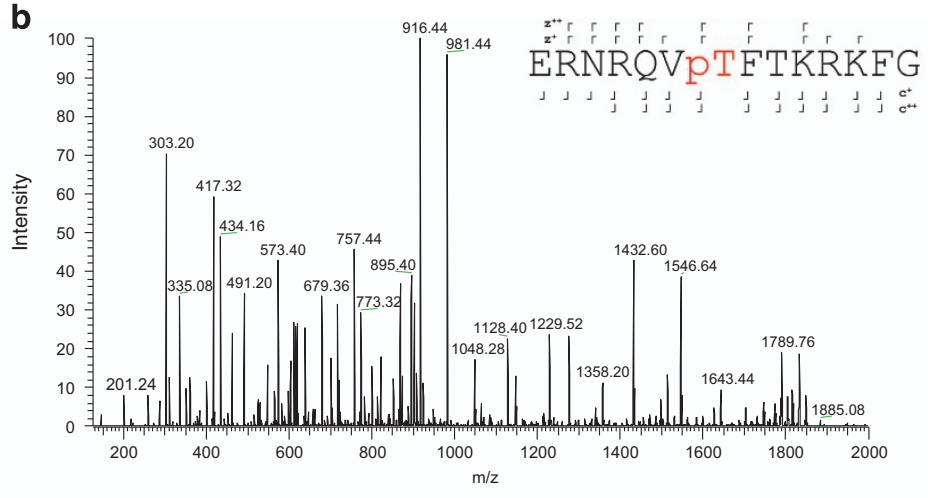

d

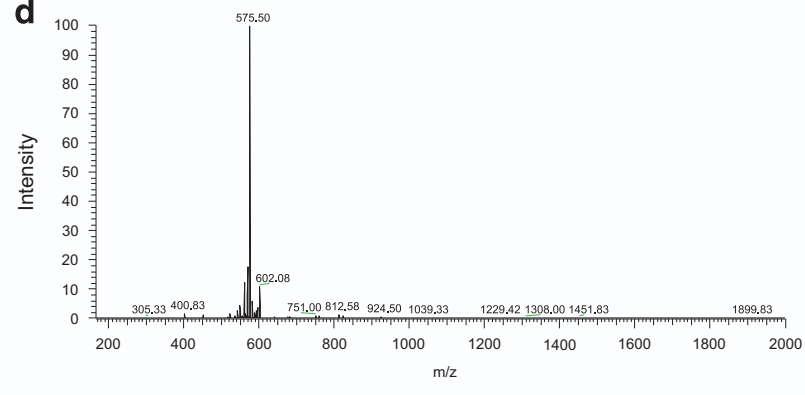

e

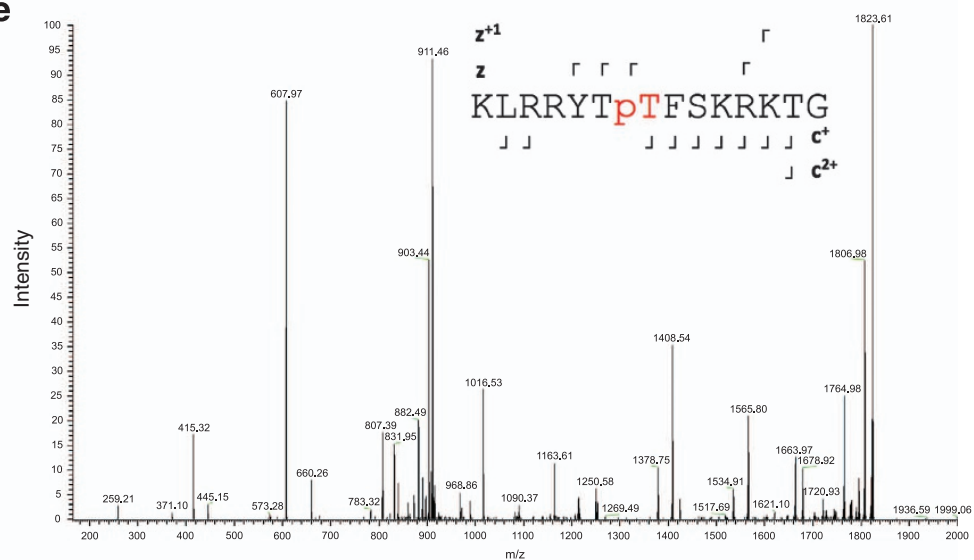

Figure 2 Identification of threonine-20 as a putative PKC $\delta$ phosphorylation residue. (a) Inset: SIM scan of native peptide (442.72, $\left.z=4^{+}\right)$and putative phospho-peptide $\left(462.48, z=4^{+}\right)$, as shown in Figure 1. The mass shift of $+19.76 \mathrm{~m} / z$ is consistent with that of a quadruply charged peptide ion. Both threonine-20 and threonine-22 are possible sites of phosphorylation. Main figure: CID MS ${ }^{2}$ spectrum of the native peptide showing a prominent neutral loss ion at $438.42 \mathrm{~m} / z$ with $z=4^{+}$. This represents a $-24.56 \mathrm{Da}$ shift consistent with a neutral loss of phosphate from threonine-20 or threonine-22 of the native peptide. (b) Fragmentation of the phospho-peptide $\left(462.48, z=4^{+}\right)$by ETD produced a near-complete $c$ and $z$ ion series with some $y$ ions also present. Analysis of this fragmentation spectra confirmed that threonine-20 is the preferred phosphorylation residue. Inset: Schematic illustrating the $z$ and $c$ ions detected by ETD. (c) SIM scan of a peptide spanning the MADS-box motif of SRF (amino acids 154-167). The unphosphorylated peptide (left) has $581.58 \mathrm{~m} / \mathrm{z}\left(z=3^{+}\right)$, while the putative phosphorylation (right in a, $\mathrm{m} / \mathrm{z}$ of 608.22 ) showing an increased $\mathrm{m} / \mathrm{z}$ of 26.64 that corresponds to $\mathrm{PO} \mathrm{O}_{3}(\mathrm{M}=80.00 \mathrm{Da}$ ). (d) $\mathrm{CID}$ $M^{2}$ spectrum of the phospho-peptide in (c) with $\mathrm{m} / z$ of 608.22 , showing a prominent neutral loss ion at $575.5 \mathrm{~m} / z$ with $z=3^{+}$. (e) ETD MS ${ }^{2}$ spectrum of SRF confirming phosphorylation of threonine-160

To assess the role of miR-133a in palmitate-induced mitochondrial depolarization mechanistically, we transfected C2C12 myoblasts with an inhibitory oligonucleotide targeting miR-133a. Control cells were transfected with a scrambled oligonucleotide. Following differentiation, cells were stained with either TMRM or MitoTracker Red CMXRos. As shown in Figure $4 e$, myotubes transfected with the miR-133a inhibitor displayed a reduced TMRM fluorescence, but an equivocal MitoTracker fluorescence, compared with control myotubes (Figures $4 \mathrm{~g}$ and $\mathrm{h}$ ). Next, we transfected myoblasts with a plasmid encoding miR-133a in order to reconstitute this
microRNA's function in palmitate-treated cells. As shown in Figure $4 \mathrm{i}$, cells expressing miR-133a were resistant to palmitate-induced disruption of mitochondrial membrane potential. We also transfected cells with T20A-VP16. Reconstitution of MEF2 function by this construct also enabled cells to be resistant to palmitate-induced mitochondrial depolarization (Figure 4i).

miR-133a regulates mitochondrial function through the mitophagy and death gene Nix. To identify a mechanism by which miR-133a regulates mitochondrial function, we 

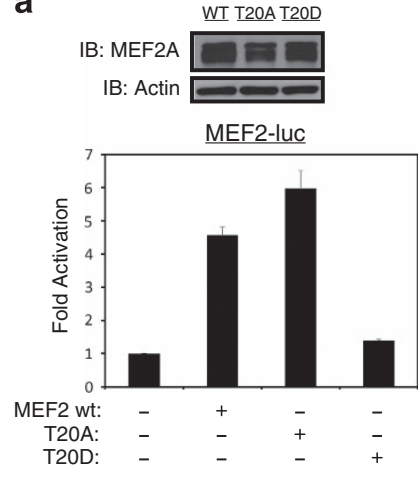

d

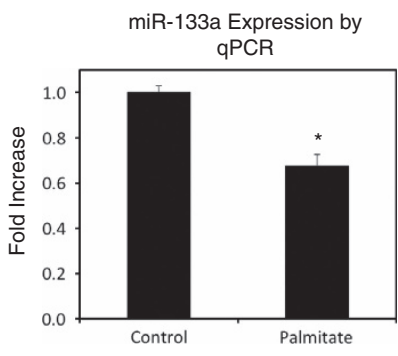

b

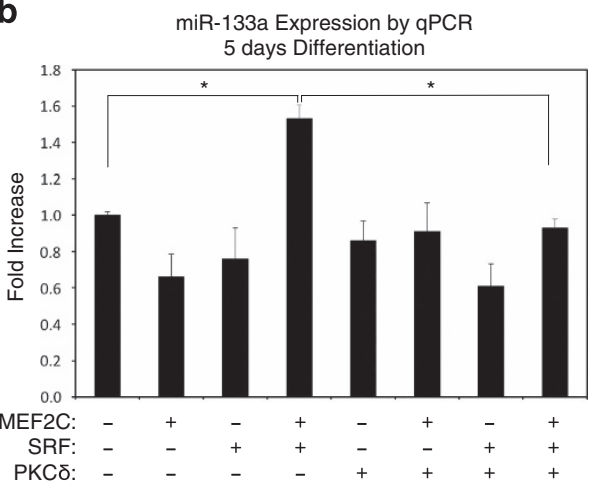

C

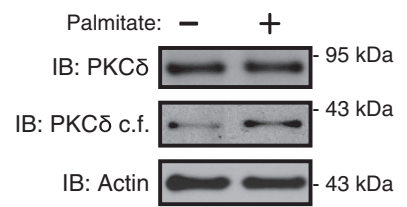

e

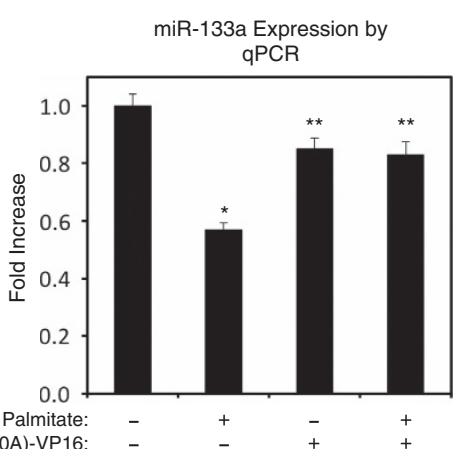

f

$$
\begin{aligned}
& \text { Palmitate: } \frac{\text { WT }}{-+} \frac{\text { DGK } \delta \text { KO }}{-+} \\
& \begin{array}{l}
\text { IP: SRF } \\
R X X p S / T
\end{array} \\
& \text { IB: PKC } \square-95 \mathrm{kDa} \\
& \text { IB: PKCठ c.f. } \square-43 \mathrm{kDa} \\
& \text { IB: SRF } 72 \mathrm{kDa} \\
& \text { IB: Actin } 43 \mathrm{kDa}
\end{aligned}
$$

Figure 3 Mutational analysis of threonine-20. (a) HEK293 cells were transfected with MEF2A (MEF2 wt), or a plasmid containing MEF2A where threonine-20 is mutated to a neutral alanine (T2OA) or phospho-mimetic aspartic acid (T2OD), as indicated, and subjected to western blot (above). 10T1/2 cells were transfected, as above, along with MEF2driven luciferase reporter gene (MEF2-luc). Extracts were subjected to luciferase assay, where $\beta$-galactosidase assay was used to correct for transfection efficiency (below). All assays were done in triplicate. (b) $\mathrm{C} 2 \mathrm{C} 12$ myoblasts were transfected with MEF2C, SRF, or PKC $\delta$, as indicated. Following recovery, cells were differentiated in low serum media for 5 days, harvested for RNA, subjected to qPCR assay. (c and d) Following 5 days of differentiation, $\mathrm{C} 2 \mathrm{C} 12$ myotubes were treated with $200 \mu \mathrm{M}$ palmitate conjugated to $2 \%$ albumin in low glucose media overnight. Control cells were treated with $2 \%$ albumin alone. Myotubes were harvested for RNA or protein, and assayed by immunoblot (c) or qPCR (d). (e) C2C12 myoblasts were transfected with MEF2-VP16 fusion where threonine-20 is mutated to a neutral alanine [MEF2(T20A)-VP16], or control plasmid. Cell was differentiated for 5 days and treated with $200 \mu \mathrm{M}$ palmitate, as indicated. Myotubes were harvested for RNA and assayed by qPCR. (f) Wild-type (WT) or diacylglycerol kinase- $\delta$ knock-out (DGK $\delta$ KO) embryonic fibroblasts treated with palmitate, as described above. Extracts were immunoprecipitated (IP) with SRF antibody and probed using an antibody that recognizes phospho-serines/threonines with arginines at the -3 position (RXXpS/T) or immunoblotted (IB), as indicated. PKC $\delta=$ catalytic fragment of PKC $\delta$. Data are represented as mean \pm S.E.M. ${ }^{*} P<0.05$ compared with control. ${ }^{* *} P<0.05$ compared with palmitate treatment

performed an in silico screen in an attempt to identify novel mRNA targets of miR-133a. This screen identified a conserved miR-133a target sequence in the 3'-untranslated region of the human and rodent Nix mRNA (Figure 5a). Thus, we expressed miR-133a in cultured myoblasts, and observed reduced protein expression of Nix, where a shRNA targeting Nix (shNix) was used as a positive control (Figure 5b). In addition, when miR-133a was expressed in myoblasts, we did not detect a change in Nix mRNA, suggesting that miR-133a inhibits Nix expression by translational block rather than mRNA degradation. To perform the reciprocal experimentation, we utilized a miR-133a inhibiting oligonucleotide, and observed increased expression of Nix protein (Figure 5c). Previous studies have shown that Nix can form a SDSresistant dimer with a predicted molecular weight of $80 \mathrm{kDa} .{ }^{31}$ Ectopic expression of the catalytic fragment of $\mathrm{PKC} \delta$ increased the protein expression of both monomeric and dimeric Nix (Figure 5d). Consistent with these findings, overnight palmitate treatment increased the protein expression of both monomeric and dimeric Nix, which was reversed by the PKC $\delta$ inhibitor rottlerin (Figure $5 \mathrm{e}$ ). To investigate the role of Nix in mitochondrial function, we transfected $\mathrm{C} 2 \mathrm{C} 12$ cells with Nix, and stained cells with TMRM. We observed reduced mitochondrial membrane potential in $\mathrm{C} 2 \mathrm{C} 12$ myoblasts that expressed Nix compared with control (Figure 5f). In addition, we observed that expression of Nix opened the mitochondrial permeability transition pore (PTP) when transfected into the cardiac H9c2 myoblasts, as evident by the loss of green mitochondrial puncta, where this effect was reversed by co-expression of the pro-survival gene $\mathrm{Bcl}-2$ (Figure $5 \mathrm{~g}$ ). Finally, to establish the role of Nix in palmitateinduced mitochondrial dysfunction, we transfected H9c2 myoblasts with shNix and evaluated mitochondrial PTP opening and membrane potential following palmitate exposure. As shown in Figure 5h, exposure to palmitate opened the mitochondrial PTP and reduced mitochondrial membrane potential; however, the shNix restored both mitochondrial puncta, and reversed the effect of palmitate on mitochondrial membrane potential (Figure 5i).

To determine the role of miR-133a in mitochondrial physiology, we evaluated oxygen consumption rate in cultured H9c2 cells. As shown in Figure 6a, overnight exposure to palmitate reduced oxygen consumption, as well as the calculated basal and maximum respiration rates when cells 
a
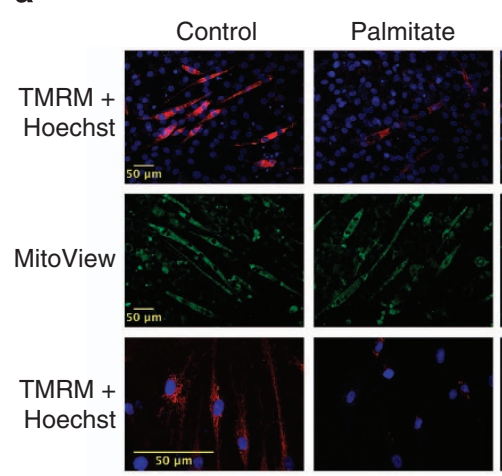

C

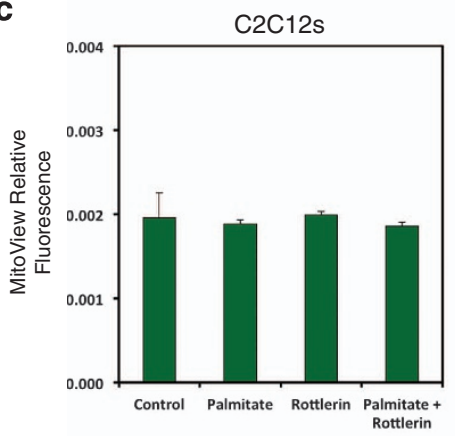

f

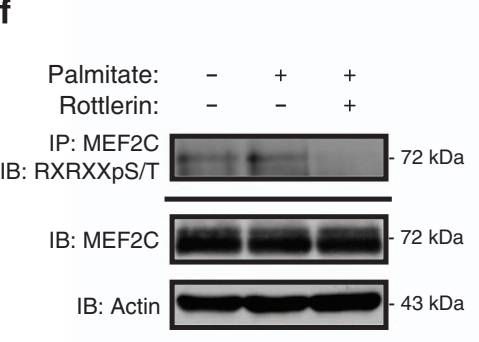

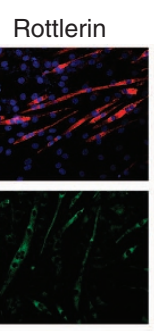

Palmitate
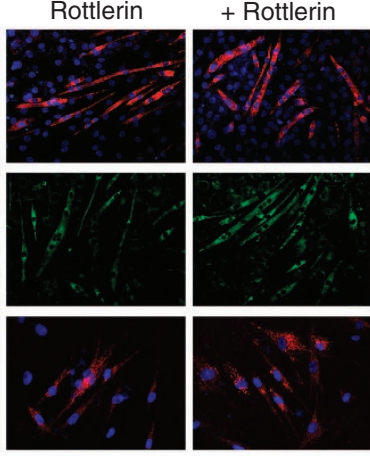

d

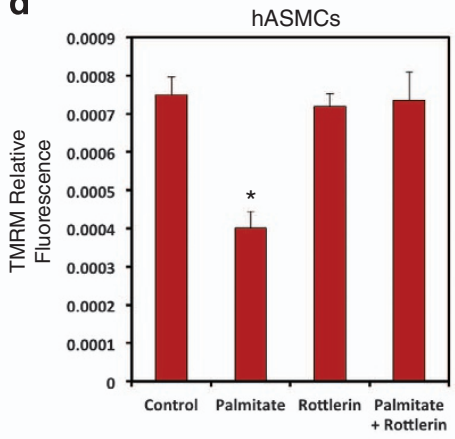

g
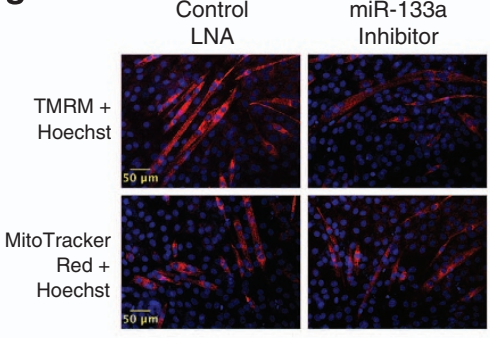

b

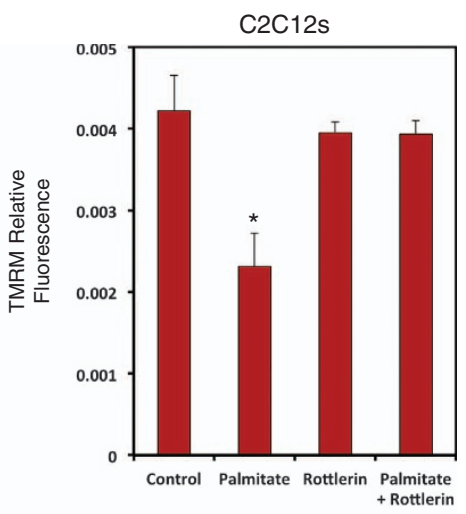

e

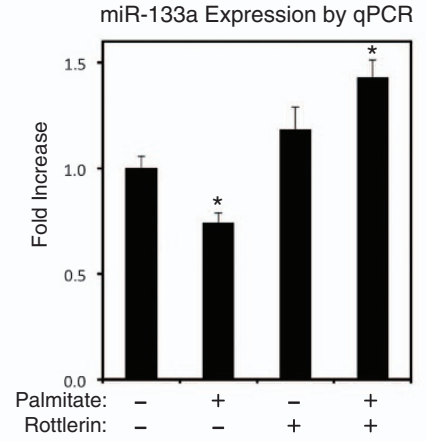

h

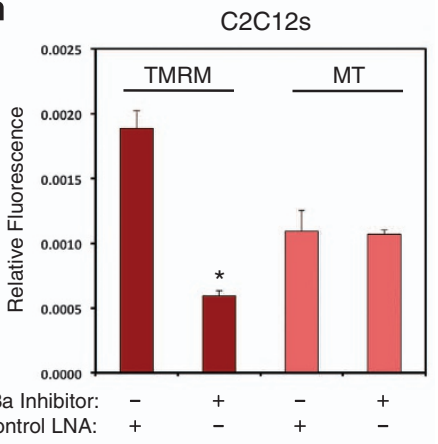

i

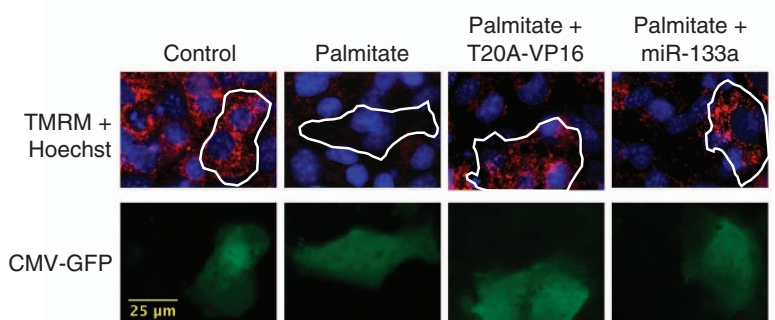

Figure 4 Palmitate-induced PKC $\delta$ activation regulates mitochondrial membrane potential through miR-133a. (a) $\mathrm{C} 2 \mathrm{C} 12$ myotubes were differentiated for 5 days (above), or hASMCs were differentiated for 2 days (below), and treated with $200 \mu \mathrm{M}$ palmitate conjugated to $2 \%$ albumin in low glucose media with or without rottlerin $(5 \mu \mathrm{M})$ overnight. Control cells were treated with $2 \%$ albumin alone. Cells were stained with TMRM, Hoechst, and MitoView Green, as indicated, and imaged by standard fluorescence techniques $(20 \times$ for $\mathrm{C2C12s;} 40 \times$ for hASMCs). (b-d) Fluorescent intensities from myotubes in (a) were quantified using ImageJ software (NIH). (e) hASMCs were treated as described in (a), harvested for RNA and subjected to qPCR analysis for miR-133a. (f) Differentiated $\mathrm{C2C12}$ myotubes were treated as in (a). Protein extracts were immunoprecipitated (IP) with an MEF2C antibody, and probed using an antibody that recognizes phospho-serines/threonines with arginines at the -5 and -3 positions (RXRXXpS/T), and immunoblotted (IB), as indicated. (g) $\mathrm{C} 2 \mathrm{C} 12$ cells were transfected with a miR-133a inhibitor oligonucleotide or a control oligonucleotide. Cells were differentiated for 5 days and imaged at $20 \times$ with TMRM, Hoechst, or MitoTracker Red CMXRos, as indicated. (h) Quantification of myotube fluorescence in (g). (i) H9c2 myoblasts were transfected with MEF2-T20A-VP16 (T20A-VP16) or miR-133a. Following 2 days of differentiation, cells were treated with $200 \mu \mathrm{M}$ palmitate conjugated to $2 \%$ albumin or $2 \%$ albumin alone as a control. CMV-GFP was included to visualize transfected cells. Data are represented as mean \pm S.E.M. ${ }^{*} P<0.05$ compared with control 
a

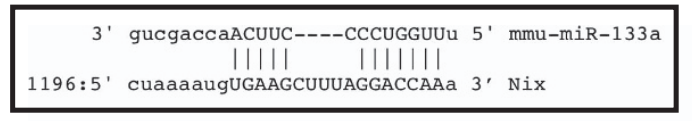

b

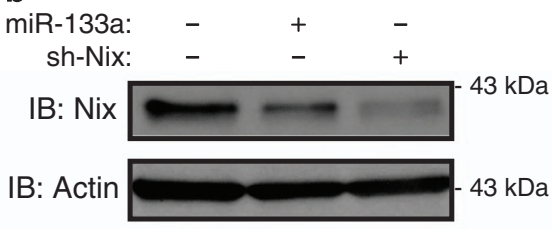

C

miR-133a

Inhibitor: - +

IB: Nix

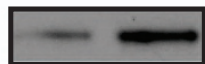

$43 \mathrm{kDa}$

IB: Actin

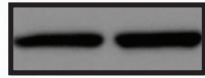
$43 \mathrm{kDa}$ d PKC8:

IB: Nix

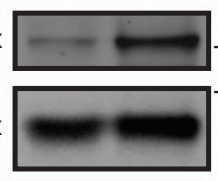

IB: PKCD

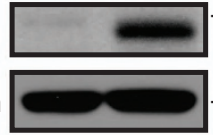

IB: Actin

$43 \mathrm{kDa}$ $-43 \mathrm{kDa}$

e

$\begin{array}{ccccc}\text { Palmitate: } & - & + & - & + \\ \text { Rottlerin: } & - & - & + & +\end{array}$

IB: Nix 72 kDa

IB: Nix

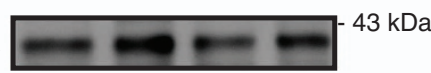

IB: Actin

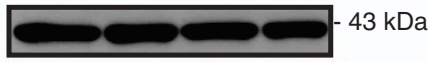

f

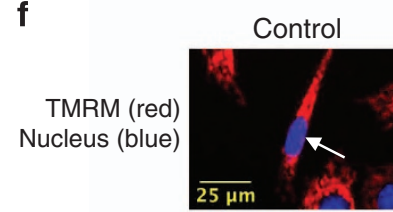

CMV-GFP

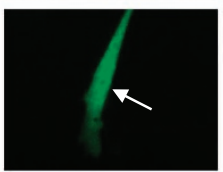

Nix
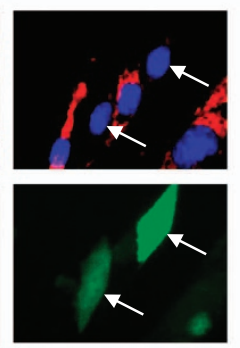

g
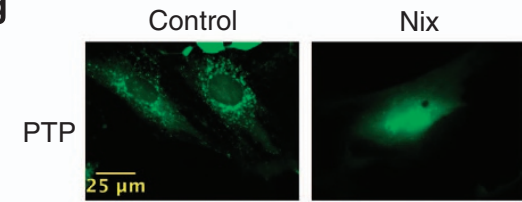

$\mathrm{Nix}+\mathrm{Bcl}-2$

dsRED
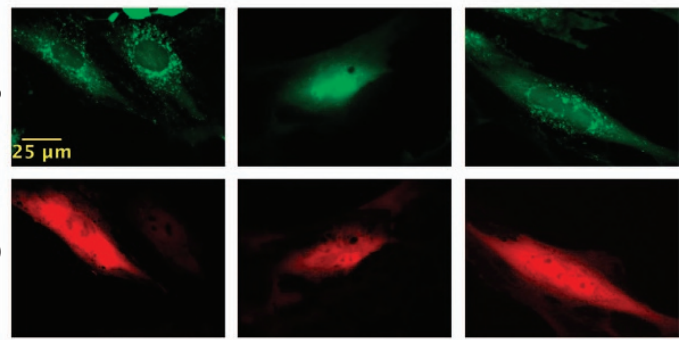

i

h

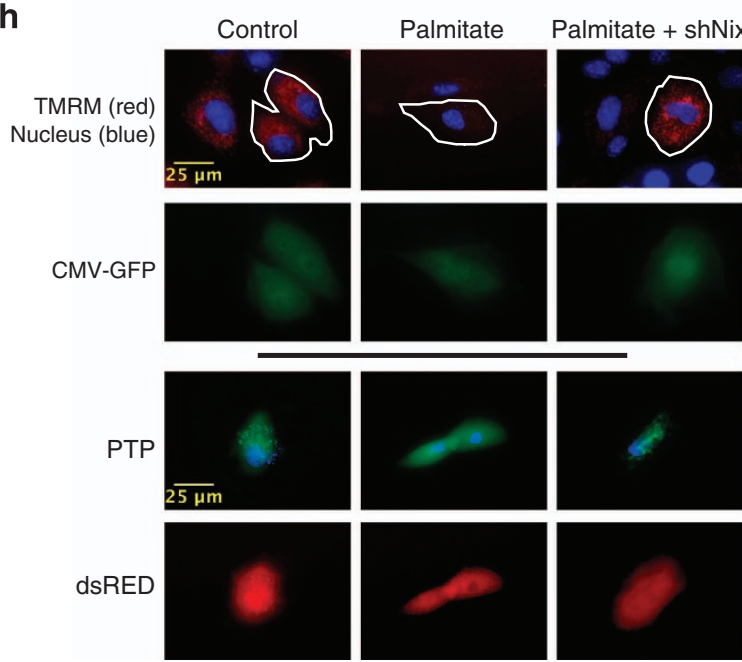

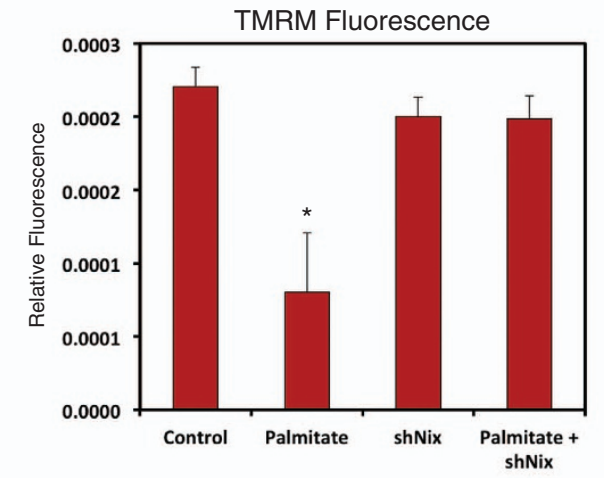

Figure 5 miR-133a regulates mitochondrial membrane potential through Nix. (a) Sequence alignment of mouse miR-133a and the 3' UTR of Nix. (b) H9c2 myoblasts were transfected with miR-133a or a shRNA targeting Nix (sh-Nix). Following protein extraction, samples were immunoblotted as indicated. (c) H9c2 cells were transfected with a miR-133a inhibitor $(50 \mu \mathrm{M})$ or a scrambled control oligonucleotide. Extracts were immunoblotted, as indicated. (d) $\mathrm{C} 2 \mathrm{C} 12$ cells were transfected with the catalytic isoform of $\mathrm{PKC} \delta$. Extracts were immunoblotted, as indicated. (e) Five-day differentiated $\mathrm{C} 2 \mathrm{C} 12$ cells were treated with $200 \mu \mathrm{M}$ palmitate conjugated to $2 \%$ albumin, or $5 \mu \mathrm{M}$ rottlerin overnight, as indicated. Protein extracts were immunoblotted, as indicated. (f) C2C12 myoblasts were transfected with Nix, or an empty vector control. CMV-GFP was included to identify transfected cells. Cells were stained with TMRM and Hoechst and imaged by standard fluorescence microscopy. Arrows indicate GFP-positive cells. (g) H9c2 cells were transfected with Nix and Bcl-2, as indicated. CMV-dsRed was used to identify transfected cells. Cells were stained with calcein-AM with cobalt chloride (5 $\mu$ M) to assess PTP opening. (h) H9c2 cells were transfected with shNix or a scrambled control shRNA. Following recovery, cells were treated with $200 \mu \mathrm{M}$ palmitate conjugated to $2 \%$ albumin overnight, and stained with TMRM and Hoechst to evaluate mitochondrial membrane potential (above) or with calcein-AM with cobalt chloride (5 $\mu \mathrm{M})$ to assess PTP opening (below). (i) Quantification of myotube fluorescence in (h). Data are represented as mean \pm S.E.M. ${ }^{*} P<0.05$ compared with control 

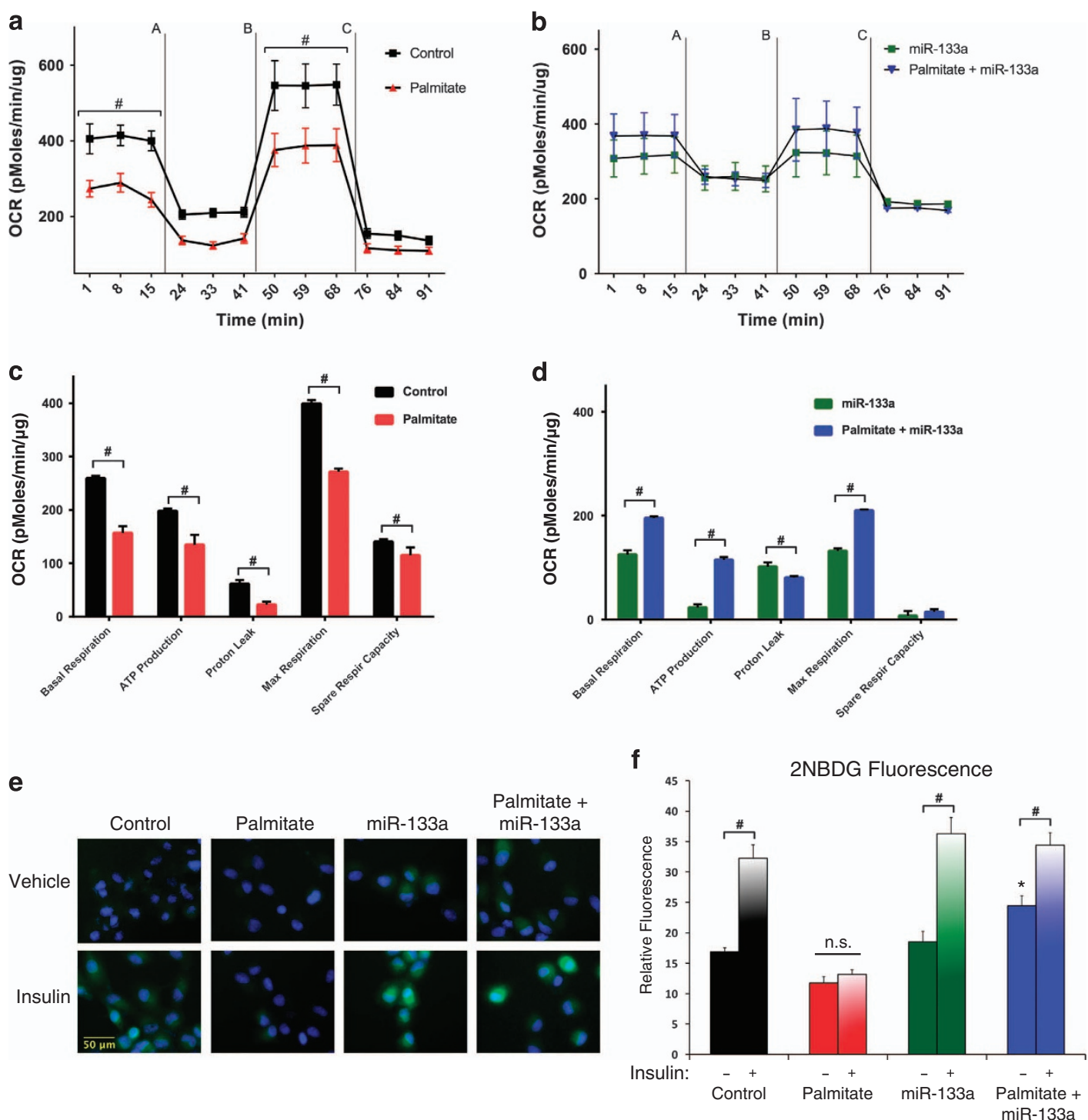

Figure 6 Evaluation of mitochondrial respiration and glucose uptake. (a) Differentiated $\mathrm{H} 9 \mathrm{c} 2$ cells were treated overnight with $200 \mu \mathrm{M}$ palmitate conjugated to $2 \%$ albumin in low glucose media. Control cells were treated with $2 \%$ albumin alone. Oxygen consumption rate (OCR) was evaluated on a Seahorse XF-24. To evaluate mitochondrial function, cells were injected with oligomycin $(1 \mu \mathrm{M})(\mathbf{a}), \operatorname{FCCP}(1 \mu \mathrm{M})(\mathbf{b})$, and antimycin $\mathrm{A}(1 \mu \mathrm{M})$ and rotenone $(1 \mu \mathrm{M})(\mathbf{c})$. (b) H9c2 cells were transfected with a miR-133a mimic $(50 \mu \mathrm{M})$ or a scrambled control oligonucleotide. Following recovery, OCR evaluated as in (a). (c and d) Calculated respiration rates from (a) and (b), respectively. (e and f) H9c2 cells were transfected as in $(\mathbf{b})$ and treated as in (a). Insulin stimulated uptake $(10 \mathrm{nM})$ was determined by 2NBDG fluorescence and quantified in (f). Data analyzed by two-way ANOVA, and represented as mean \pm S.E.M. ${ }^{\#} P<0.05$ between groups, ${ }^{\star} P<0.05$ compared with control

were stressed with oligomycin (a), FCCP (b), and antimycin A and rotenone (c) (Figure $6 \mathrm{c}$ ). ${ }^{32}$ However, when cells were transfected with a miR-133a mimicking oligonucleotide, the palmitate-induced drop in oxygen consumption was prevented (Figure 6b), where control cells were transfected with a scrambled oligonucleotide. Furthermore, the calculated basal and maximum respiration rates were increased when miR-133a mimic-treated cells were exposed to palmitate (Figure $6 \mathrm{~d}$ ), suggesting that improved mitochondrial function enabled cells to metabolize the available palmitate. Finally, we determined whether restoration in mitochondrial function translated into improved insulin-stimulated glucose uptake. As shown in Figures $6 e$ and $f$, overnight exposure to palmitate prevented insulin-stimulated glucose uptake in differentiated
$\mathrm{H} 9 \mathrm{c} 2$ cells, determined by the fluorescence glucose analog 2NBDG, which was restored when cells were treated with a miR-133a mimic. Interestingly, basal glucose uptake was also increased in cells treated with the miR-133a mimic and exposed to palmitate.

Evaluation of miR-133a and Nix expression in vivo. To determine the in vivo relevance of this genetic pathway in muscle tissues, we utilized a rodent model of gestational diabetes, as fetal exposure to diabetes during pregnancy increases the risk for early-onset insulin resistance in the offspring and may program metabolism. ${ }^{4,5}$ Rats exposed to diabetes during gestation become insulin resistant by 15 weeks of age, a phenotype that is exacerbated by the 


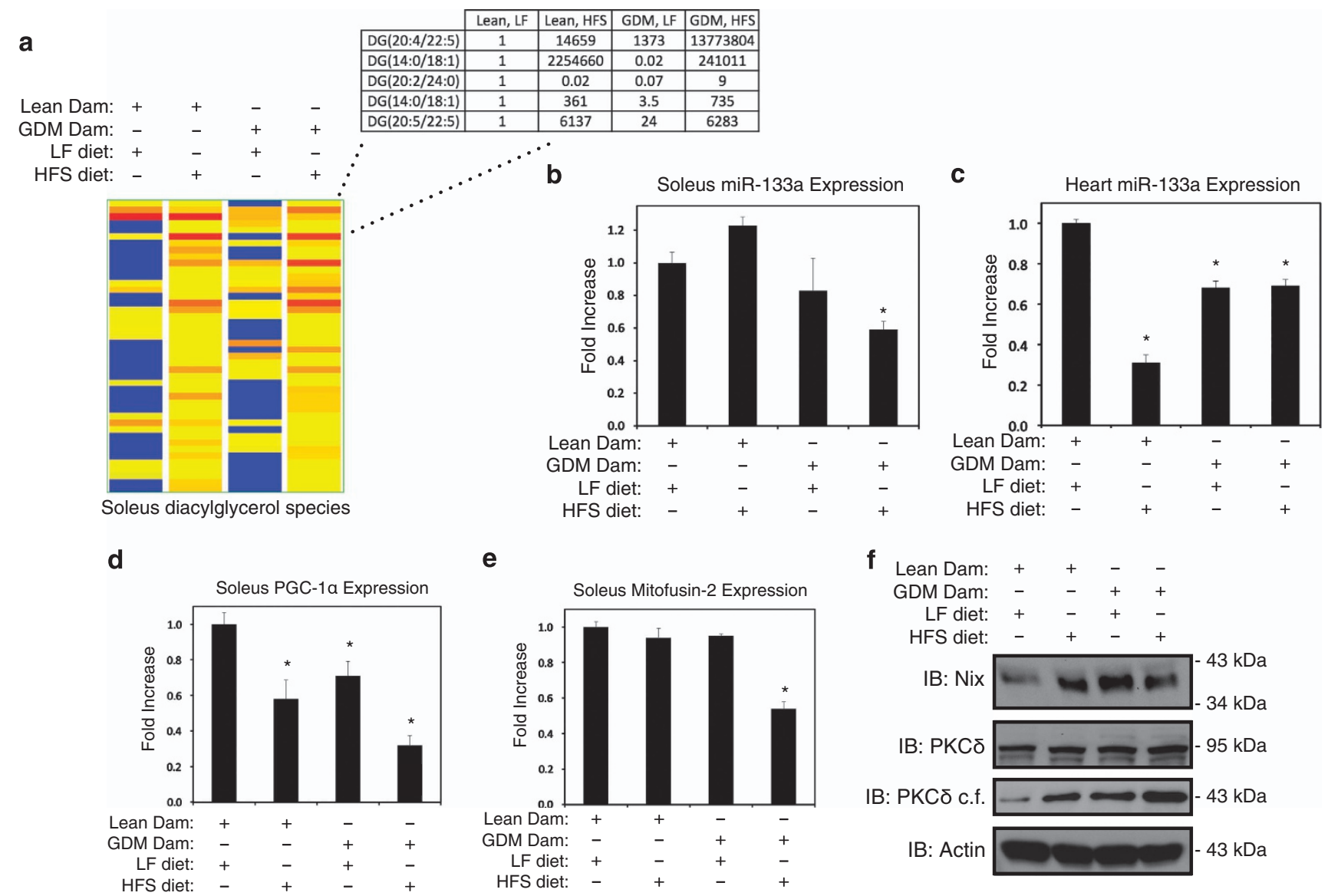

Figure 7 miR-133a expression in vivo. (a) Metabolomics analysis of 44 species of diacylglycerols from soleus muscle excised from LF, or HFS, and a normal pregnancy (Lean Dam), or gestational diabetes (GDM Dam) during development, as indicated. Five highly abundant diacylglycerols are highlighted in the chart. Blue $=$ low abundance, yellow $=$ medium low abundance, orange $=$ medium high abundance, red $=$ high abundance. (b-e) Rat soleus muscle or heart tissue was excised and total RNA was extracted, from rodents treated as described in (a). qPCR analysis was performed using the $\Delta \Delta \mathrm{CT}$ method, where RNU6 was used as an internal control for miR-133a, and $\beta$-actin was used as a control for PCG-1 $a$ and mitofusin-2. (f) Protein extracts from rat soleus muscle were subjected to immunoblot analysis, as indicated. PKC $\delta$ catalytic fragment (PKC $\delta$ c.f.). Data are represented as mean \pm S.E.M. ${ }^{*} P<0.05$ compared with control

postnatal consumption of a high-fat and sucrose (HFS) diet. ${ }^{5}$ To further define the metabolic alterations induced by exposure to gestational diabetes in muscle tissue, we performed metabolomics analysis by mass spectrometry using extracts enriched for lipid-soluble metabolites. This screen identified 44 species of diacylglycerols varying in the composition of their fatty acid chains (Supplementary Table 2). In the offspring of normoglycemic lean dams, numerous diacylglycerol species were increased by the HFS diet (Figure 7a). However, exposure to maternal diabetes increased diacylglycerols in the soleus muscle of both low fat (LF) and HFS-fed offspring, suggesting the presence of a programming effect on soleus muscle (Figure 7a). Thus, we hypothesized that the accumulation of diacylglycerol species would provide an activating stimulus for PKC $\delta$. In support of this, we observed that miR-133a expression was reduced by $40 \%$ in the soleus and heart of animals exposed to both gestational diabetes and a HFS diet (Figures $7 b$ and $c$ ). In addition, we evaluated the expression of mitochondrial marker genes in the soleus muscle of our rodent model. PGC-1 $1 a$ expression was reduced by both the postnatal consumption of the HFS diet and fetal exposure to gestational diabetes, and the consumption of HFS diets by the offspring of diabetic dams caused an additive suppression of PGC-1a expression (Figure 7d). Moreover, mitofusin-2 expression was also reduced in the gestational diabetes offspring fed HFS diets (Figure 7e). In addition, we observed an increased expression of Nix in the soleus of rats exposed to the HFS diet or gestational diabetes (Figure 7f), concurrent with increased expression of the catalytic fragment of $\mathrm{PKC} \delta$. These findings suggest that developmental programming of diacylglycerol metabolism and miR-133a expression influences mitochondrial markers, and Nix expression, in the offspring.

\section{Discussion}

PKC signaling has been implicated in lipotoxicity and diabetic complications in multiple cell types ${ }^{22}$ although the precise molecular mechanisms have not yet been defined in muscle tissues. Previously, our research group demonstrated that novel PKC isoforms could activate the C-terminus of MEF2 
proteins utilizing Gal4-DNA binding domain fusion proteins. ${ }^{33}$ In addition, novel PKC isoforms activate a PKD-dependent signaling cascade resulting in liberation of MEF2 from HDAC5 repression during cardiac growth. ${ }^{34}$ However, during the course of our investigations, we observed that expression of PKC $\delta$ could inhibit MEF2 activity in some cellular contexts. Utilizing three independent muscle cell lines, an in vivo model, and mouse embryonic fibroblasts genetically deficient in DGK $\delta$, we characterized a novel pathway initiated by $\mathrm{PKC} \delta$ signaling during lipotoxicity that converges on MEF2 and SRF transcription factors to regulate muscle gene expression and mitochondrial membrane potential. Detailed mass spectrometry analysis revealed that PKC $\delta$ phosphorylates MEF2 proteins at threonine-20 and SRF at threonine-160, a conserved MADS-box residue. Downstream, collaborative regulation of miR-133a expression by MEF2C and SRF is attenuated by $\mathrm{PKC} \delta$ phosphorylation of these transcription factors. Importantly, expression of either miR-133a or an active MEF2 fusion protein, which cannot be phosphorylated by $\mathrm{PKC} \delta$, reverses palmitate-induced mitochondrial dysfunction.

Recently, phosphorylation of Drosophila MEF2 at threonine20 was shown to direct MEF2 activity between immune activation and metabolic function. ${ }^{30}$ In flies, MEF2 is normally phosphorylated at threonine-20 to promote anabolic gene expression. However, during infection MEF2 is dephosphorylated and targeted to genes involved with immune function at the expense of anabolic nutrient storage. At first, these results may seem contrary to the findings of the present study. However, regulation of MEF2 and SRF by phosphorylation at the conserved MADS-box motif, and its downstream effects on miR-133a and Nix, may have evolved to limit mitochondrial metabolism and divert nutrients to anabolic storage or cell growth during differentiation. Thus, the novel genetic pathway identified in the present study may represent an anabolic survival pathway, maintained through evolution in part due to the conservation of the MADS domain.

One of the most intriguing findings of the present study is the identification of Nix as a miR-133a target. Previous studies have implicated both Nix and miR-133a in the regulation of mitochondrial function and programmed cell death in multiple cell types, ${ }^{19,35-37}$ and our data strongly suggest that miR-133a is dependent on Nix for mitochondrial membrane potential regulation in muscle tissues. Furthermore, both Nix and miR-133a are involved in pathological cardiac remodeling. ${ }^{38-40}$ Thus, our findings may represent an important mechanism involved in diabetes-induced heart disease and have an important role in the progression to heart failure following cardiac injury.

In summary, these studies document a novel signaling cascade triggered by lipotoxicity, and converging on MEF2 and SRF transcription factors to regulate the expression of miR-133a during muscle development and post-natal remodeling. Repression of miR-133a expression ultimately regulates mitochondrial function, through the $\mathrm{Bcl}-2$ family member Nix, which may have implications to pathological states such as insulin resistance and cardiovascular disease.

\section{Materials and Methods}

Bioinformatics screen to predict functional transcription factor

interactions. Muscle gene expression data were compiled from the profile published by Zhang et al. ${ }^{41}$ Genomic sequence representing the proximal promoter region $(-1000$ to $+200 \mathrm{bp})$ of 46 muscle genes was extracted from the Database of Transcriptional Factor Start Sites (DBTSS) and used for this analysis. Position weight matrices of all known mouse transcription factors were collected from the TRANSFAC and Wasserman-Fickett databases. We determined the conserved index $(\mathrm{Ci})$ by calculating the degree of conservation of individual nucleotides in the matrix as a numerical value. In this model, Ci varies between 0 and 100, where 100 represents a position with total conservation of one nucleotide, and 0 represents equal distribution of all four possible nucleotides. Using this approach, we defined a core binding region as a region with four consecutive nucleotide positions with the highest $\mathrm{Ci}$ values, and used this core binding region to reduce the number of matches in the position weight matrices. We calculated the optimized matrix threshold and screened the promoter regions of the target sequences with the position weight matrices and optimized matrix threshold to detect interacting partners of MEF2 proteins based on the co-occurrence of cis-regulatory elements.

Plasmids. The MEF2 plasmids were described previously. ${ }^{28,42,43}$ The plasmid expressing the $\mathrm{PKC} \delta$ catalytic fragment was kindly provided by $\mathrm{K}$ Wheaton. The miR-133a expression plasmid was purchased from Addgene (Principal Investigator David Bartel, plasmid 26326). ${ }^{44}$ The shRNA targeting SRF was based on the targeting sequence previously described by Medjkane et al. (5'-CTGCAGCC CATGATCACCA $\left.-3^{\prime}\right) .{ }^{45}$ Sense and antisense oligonucleotides containing the target sequence were purchased from Sigma Aldrich (Oakville, ON, Canada), annealed, and ligated into pSilencer 3.0 H1 (Ambion, ThermoFisher, Burlington, ON, Canada). The Nix (Bnip3L), shNix, and Bcl-2 plasmids were purchased from Addgene (Principal Investigator Wafik El-Deiry, plasmids 17467 and 17469, and Principal Investigator Clark Distelhorst, plasmid 18003). ${ }^{46,47}$

Cell culture and transfections. All cell lines were maintained in Dulbecco's modified Eagle's medium (DMEM; Hyclone, Fisher Scientific, Ottawa, ON, Canada), containing penicillin, streptomycin, and $10 \%$ fetal bovine serum (Hyclone) at $37^{\circ} \mathrm{C}$ and $5 \% \mathrm{CO}_{2}$. Generation of the hTERT senescent-resistant hASMC was described previously, ${ }^{48}$ as were the DGK $\delta$-null fibroblasts. ${ }^{29}$ C2C12 and hASMCs were transfected using JetPrime Polyplus reagent, and the H9c2 cell line was transfected using Qiagen's Polyfect reagent, as per the manufacturer's instructions. C2C12 was differentiated by re-feeding cells in $2 \%$ fetal bovine serum (Hyclone) for to $2-5$ days, as indicated in the figure legends, while $\mathrm{H} 9 \mathrm{c} 2$ cells were differentiated in $1 \%$ fetal bovine serum (Hyclone) for $24-48 \mathrm{~h}$. Palmitate conjugation and treatments were performed as described by Chavez et al. ${ }^{49}$

In vitro kinase assay. Synthetic peptides (Fisher Scientific) were resuspended in molecular biology grade water at a concentration of $1 \mathrm{mg} / \mathrm{ml}$. Peptide sequences used were MEF2 wild-type amino acids 14-27: ERNRQVTFTKRKFG, MEF2 threonine-20 mutation: ERNRQVAFTKRKFG, SRF amino acids 154-167: KLRRYTTFSKRKTG. These peptides were used as the substrate in a $\operatorname{PKC} \delta$ kinase assay kit (SignalChem, Richmond, BC, Canada) according to the manufacturer's instructions, with the exception that $\left[{ }^{32} \mathrm{P}\right]$-ATP was replaced with fresh molecular biology grade ATP. The manufacturer's CREBtide synthetic peptide substrate (KRREILSRRPSYR) was used as a positive control in each assay. Following incubation at $30^{\circ} \mathrm{C}$ for $15 \mathrm{~min}$, reactions were frozen at $-80^{\circ} \mathrm{C}$ before mass spectrometry analysis.

Phospho-peptide mapping. Before mass spectrometry analysis, kinase assays were prepared using $\mathrm{C}_{18}$ ZipTips (EMD Millipore, Etobicoke, ON, Canada), according to the manufacturer's protocol, to desalt and concentrate peptides. Samples in $50 \%$ acetonitrile and $0.1 \%$ formic acid were introduced into a linear iontrap mass spectrometer (LTQ XL: ThermoFisher, San Jose, CA, USA) via static nanoflow, using a glass capillary emitter (PicoTip: New Objective, Woburn, MA, USA). All spectra were acquired using the ZoomScan setting. For $\mathrm{MS}^{2}, \mathrm{CID}$ or ETD was used. For the former, collision energy was set to $25 \%$; for the latter a reaction time of $100 \mathrm{~ms}$ with fluoranthane was set. Spectra were sequenced de novo manually.

Immunoprecipitation and immunoblotting. Protein extractions were achieved using a RIPA lysis buffer containing protease inhibitors and phosphatase inhibitors (Santa Cruz, Dallas, TX, USA). Protein concentrations were determined using a Bio-Rad Canada (Mississauga, ON, Canada) Protein assay kit. Extracts were resolved using SDS-PAGE and transferred onto a PVDF membrane. Immunoblotting was carried out using appropriate primary antibody in 5\% powdered 
milk or BSA in TBST. Appropriate horseradish peroxidase-conjugated secondary antibody (Jackson ImmunoResearch Laboratories, West Grove, PA, USA; 1 : 4000) was used in combination with chemiluminescence to visualize bands. Immunoprecipitations utilized the Immunocruz kit (Santa Cruz), described previously, ${ }^{43}$ and complexes were probed by immunoblot using the RXRXXpS/T or RXXpS/T phospho-antibodies from Cell Signaling Technology (Danvers, MA, USA).

Fluorescent staining. MitoTracker Red CMXRos was purchased from Cell Signaling Technology and applied to cells for $30 \mathrm{~min}$. Following incubation, cells were re-fed standard DMEM. TMRM, Calcein-AM, MitoView Green, and Hoechst 33342 were purchased from Biotium (Hayward, CA, USA). PTP imaging was performed by quenching the cytosolic Calcein-AM signal with $5 \mu \mathrm{M}$ cobalt chloride during the incubation period. All imaging was done on an Olympus IX70 inverted microscope (Toronto, ON, Canada) with QImaging Retiga SRV Fast 1394 camera (Surrey, BC, Canada) using NIS Elements AR 3.0 software (Nikon Instruments Inc., Melville, NY, USA). Quantification, scale bars, and processing were done on ImageJ software (NIH, Bethesda, MD, USA).

Mitochondrial respiration and glucose uptake. Mitochondrial respiration was determined on a Seahorse XF-24 Extracellular Flux Analyzer (Seahorse Bioscience, North Billerica, MA, USA), as described previously. ${ }^{32}$ Calculated respiration rates were determined as per manufacturer's instructions (Mito Stress Kit; Seahorse Bioscience). Insulin-stimulated glucose uptake was evaluated in differentiated $\mathrm{H} 9 \mathrm{c} 2$ cells incubated in the presence or absence of $10 \mathrm{nM}$ insulin in phosphate-buffered saline (PBS) for $15 \mathrm{~min}$, followed by $15 \mathrm{~min}$ with the inclusion of the fluorescent D-glucose analog 2NBDG $(200 \mu \mathrm{M}$; Molecular Probes, ThermoFisher). Cells were imaged by standard techniques and quantified using ImageJ.

Diet-induced gestational diabetes model. All procedures in this study were approved by the Animal Welfare Committee of the University of Manitoba, which adheres to the principles for biomedical research involving animals developed by the Council for International Organizations of Medical Sciences. Female Sprague-Dawley rats were obtained at 4 weeks of age (University of Manitoba Colony) and randomly allocated to a LF diet (10\% fat, Research Diets D12450B) or a HFS diet (45\% fat, Research Diets D12451) for 6 weeks to induce pre-gestational glucose intolerance. ${ }^{5,50}$ The female rats continued on their respective diets throughout pregnancy and weaning. The high-fat/sucrose-fed female rats developed hyperglycemia characteristic of gestational diabetes (GDM) while pregnant. Pups were weaned at 3 weeks of age and randomly assigned to either LF or HFS diets for 12 weeks, creating four experimental groups: the offspring of lean mothers fed LF or HFS diets and the offspring of GDM mothers fed LF or HFS diets. For tissue analysis, rats were euthanized by overdose of sodium pentobarbital, and the heart and soleus muscles were dissected, rinsed in PBS, and immediately clamp frozen in liquid nitrogen.

Quantitative PCR. Total RNA was extracted from cultured cells and pulverized frozen tissue by the TRIzol method. For microRNA analysis, all primers were purchased from Quanta BioSciences (Gaithersburg, MD, USA). cDNA was generated using QScript MicroRNA cDNA Synthesis kit (Quanta BioSciences) and q-RT-PCR performed using PerfeCTa SYBR green super mix on a Applied Biosystems 7500 Real-Time PCR Instrument (ThermoFisher), and normalized to RNU6 expression. For mRNA analysis, following column purification using Qiagen RNeasy kit and DNase treatment (Qiagen, Toronto, ON, Canada), cDNA was generated with QScript CDNA super mix (Quanta BioSciences) and analyzed as described above, and normalized to $\beta$-actin expression. Primers used were PGC-1a total: Forward 5'-CAGCTTTCTGGGTGGATTGA-3' and Reverse $5^{\prime}$-GCTCATTG TTGTACTGGTTGGA-3', Mitofusin-2: Forward 5'-CTCTCAAGCACTTTGTCACTG C-3' and Reverse 5'-TGTATTCCTGTGGGTGTCTTCA-3', $\beta$-actin: Forward 5'-TT GCTGACAGGATGCAGAAG-3' and Reverse 5'-TAGAGCCACCAATCCACACA-3'.

Mass spectrometry metabolomics analysis. Analysis of total soleus lipids was performed using a lipid soluble extraction, and analysis was preformed as described previously. ${ }^{5}$ Briefly, lipid extracts were reconstituted with $100 \mu \mathrm{l}$ of $80 \%$ acetonitrile prepared in deionized water. Metabolomics analysis was performed on a 1290 Infinity Agilent high-performance liquid chromatography (HPLC) system coupled to a 6538 UHD Agilent Accurate Q-TOF LC/MS equipped with a dual electrospray ionization source. A $3 \times 50 \mathrm{~mm}, 2.7 \mu$ Agilent Poroshell column was used to separate metabolites while the column temperature was maintained at $60^{\circ} \mathrm{C}$. The mass detection was operated using dual electrospray with reference ions of $\mathrm{m} / \mathrm{z} 121.050873$ and 922.009798 for positive mode; and $\mathrm{m} / \mathrm{z} 119.03632$ and 980.016375 for negative mode. The workflow utilized for data processing comprised several algorithms used by Agilent Mass Hunter Qualitative (MHQ, B.05, Agilent Technologies, Mississauga, ON, Canada) and by Mass Profiler Professional (MPP, 12.6, Agilent Technologies).

\section{Conflict of Interest}

The authors declare no conflict of interest.

Acknowledgements. We thank Drs Keith Wheaton and Robert Perry for providing the PKC $\delta$ and MEF2-VP16 fusion plasmids, respectively. We also thank Tao Fan for MS technical support; Dr Laura Cole and Edward Mejia for technical assistance with respiration experiments; and Dr William Diehl-Jones for technical assistance and helpful comments on the manuscript. JWG is supported by NSERC Canada; and VWD, AJH, GMH, and JCM are supported by CIHR. GMH is supported by the Heart and Stroke Foundation of Canada. Seed funding for this project was provided by the Manitoba Medical Service Foundation, Children's Hospital Foundation of Manitoba, and the Manitoba Health Research Council to VWD and JWG. VWD is the Dr JA Moorhouse Fellow of the Diabetes Foundation of Manitoba. AJH and GMH are supported through the Canada Research Chairs program, and JCM is a McLaughlin Research Chair. JWG, VWD, GMH, and AJH are members of the DEVOTION Research Cluster. WM, LN, and SP are supported by scholarships from the Children's Hospital Foundation of Manitoba. TJP was supported by a studentship from the Manitoba Health Research Council.

1. Florini JR, Ewton DZ, Magri KA. Hormones, growth factors, and myogenic differentiation. Annu Rev Physiol 1991; 53: 201-216.

2. Harvey RP. Patterning the vertebrate heart. Nat Rev Genet 2002; 3: 544-556.

3. Owens GK, Kumar MS, Wamhoff BR. Molecular regulation of vascular smooth muscle cell differentiation in development and disease. Physiol Rev 2004; 84: 767-801.

4. Bayol SA, Simbi BH, Stickland NC. A maternal cafeteria diet during gestation and lactation promotes adiposity and impairs skeletal muscle development and metabolism in rat offspring at weaning. J Physiol 2005; 567: 951-961.

5. Pereira TJ, Fonseca MA, Campbell KE, Moyce BL, Cole LK, Hatch GM et al. Maternal obesity characterized by gestational diabetes increases the susceptibility of rat offspring to hepatic steatosis via a disrupted liver metabolome. J Physiol 2015; 593: 3181-3197.

6. Parker MH, Seale P, Rudnicki MA. Looking back to the embryo: defining transcriptional networks in adult myogenesis. Nat Rev Genet 2003; 4: 497-507.

7. Kelly RG. Molecular inroads into the anterior heart field. Trends Cardiovasc Med 2005; 15: 51-56.

8. Majesky MW. Developmental basis of vascular smooth muscle diversity. Arterioscler Thromb Vasc Biol 2007; 27: 1248-1258.

9. Potthoff MJ, Wu H, Arnold MA, Shelton JM, Backs J, McAnally J et al. Histone deacetylase degradation and MEF2 activation promote the formation of slow-twitch myofibers. J Clin Invest 2007; 117: 2459-2467.

10. Potthoff MJ, Olson EN. MEF2: a central regulator of diverse developmental programs Development 2007; 134: 4131-4140.

11. Cox DM, Du M, Marback M, Yang ECC, Chan J, Siu KWM et al. Phosphorylation motifs regulating the stability and function of myocyte enhancer factor 2 A. J Biol Chem 2003; 278: 15297-15303.

12. Rampalli S, Li L, Mak E, Ge K, Brand M, Tapscott SJ et al. p38 MAPK signaling regulates recruitment of Ash2L-containing methyltransferase complexes to specific genes during differentiation. Nat Struct Mol Biol 2007; 14: 1150-1156.

13. Du M, Perry RLS, Nowacki NB, Gordon JW, Salma J, Zhao J et al. Protein kinase A represses skeletal myogenesis by targeting myocyte enhancer factor 2D. Mol Cell Biol 2008; 28: 2952-2970.

14. Miano JM. Serum response factor: toggling between disparate programs of gene expression. J Mol Cell Cardiol 2003; 35: 577-593.

15. Miano JM, Ramanan N, Georger MA, de Mesy Bentley KL, Emerson RL, Balza RO et al. Restricted inactivation of serum response factor to the cardiovascular system. Proc Natl Acad Sci USA 2004; 101: 17132-17137.

16. Li S, Czubryt MP, McAnally J, Bassel-Duby R, Richardson JA, Wiebel FF et al. Requirement for serum response factor for skeletal muscle growth and maturation revealed by tissuespecific gene deletion in mice. Proc Natl Acad Sci USA 2005; 102: 1082-1087.

17. Czubryt MP, McAnally J, Fishman GI, Olson EN. Regulation of peroxisome proliferatoractivated receptor gamma coactivator 1 alpha (PGC-1 alpha) and mitochondrial function by MEF2 and HDAC5. Proc Natl Acad Sci USA 2003; 100: 1711-1716. 
18. Liu N, Williams AH, Kim Y, McAnally J, Bezprozvannaya S, Sutherland LB et al. An intragenic MEF2-dependent enhancer directs muscle-specific expression of microRNAs 1 and 133. Proc Natl Acad Sci USA 2007; 104: 20844-20849.

19. Liu N, Bezprozvannaya S, Shelton JM, Frisard MI, Hulver MW, McMillan RP et al. Mice lacking microRNA 133a develop dynamin 2-dependent centronuclear myopathy. J Clin Invest 2011; 121: 3258-3268.

20. Torella D, laconetti C, Catalucci D, Ellison GM, Leone A, Waring CD et al. MicroRNA-133 controls vascular smooth muscle cell phenotypic switch in vitro and vascular remodeling in vivo. Circ Res 2011; 109: 880-893.

21. Coll $T$, Jové $M$, Rodríguez-Calvo $R$, Eyre E, Palomer $X$, Sánchez RM et al. Palmitatemediated downregulation of peroxisome proliferator-activated receptor-gamma coactivator 1alpha in skeletal muscle cells involves MEK1/2 and nuclear factor-kappaB activation. Diabetes 2006; 55: 2779-2787.

22. Gordon JW, Dolinsky VW, Mughal W, Gordon GRJ, McGavock J. Targeting skeletal muscle mitochondria to prevent type 2 diabetes in youth. Biochem Cell Biol 2015: 1-14.

23. Gordon JW, Pagiatakis C, Salma J, Du M, Andreucci JJ, Zhao J et al. Protein kinase A-regulated assembly of a MEF2\{middle dot\}HDAC4 repressor complex controls c-Jun expression in vascular smooth muscle cells. J Biol Chem 2009; 284: 19027-19042.

24. Wheaton K, Riabowol K. Protein kinase $\mathrm{C}$ delta blocks immediate-early gene expression in senescent cells by inactivating serum response factor. Mol Cell Biol 2004; 24 7298-7311.

25. Zhang J, Ney PA. Role of BNIP3 and NIX in cell death, autophagy, and mitophagy. Cell Death Differ 2009; 16: 939-946.

26. Chen S, Puthanveetil P, Feng B, Matkovich SJ, Dorn GW II, Chakrabarti S. Cardiac miR-133a overexpression prevents early cardiac fibrosis in diabetes. J Cell Mol Med 2014; 18: $415-421$

27. Chen J-F, Mandel EM, Thomson JM, Wu Q, Callis TE, Hammond SM et al. The role of microRNA-1 and microRNA-133 in skeletal muscle proliferation and differentiation. Nat Genet 2006; 38: 228-233.

28. Perry RLS, Yang C, Soora N, Salma J, Marback M, Naghibi L et al. Direct interaction between myocyte enhancer factor 2 (MEF2) and protein phosphatase 1alpha represses MEF2-dependent gene expression. Mol Cell Biol 2009; 29: 3355-3366.

29. Shulga YV, Loukov D, Ivanova PT, Milne SB, Myers DS, Hatch GM et al. Diacylglycerol kinase delta promotes lipogenesis. Biochemistry 2013; 52: 7766-7776.

30. Clark RI, Tan SWS, Péan CB, Roostalu U, Vivancos V, Bronda $\mathrm{K}$ et al. MEF2 is an in vivo immune-metabolic switch. Cell 2013; 155: 435-447.

31. Chen G, Cizeau J, Vande Velde C, Park JH, Bozek G, Bolton J et al. Nix and Nip3 form a subfamily of pro-apoptotic mitochondrial proteins. J Biol Chem 1999; 274 7-10.

32. Cheung KG, Cole LK, Xiang B, Chen K, Ma X, Myal Y et al. Sirtuin-3 (SIRT3) protein attenuates doxorubicin-induced oxidative stress and improves mitochondrial respiration in H9c2 cardiomyocytes. J Biol Chem 2015; 290: 10981-10993.

33. Ornatsky OI, Cox DM, Tangirala P, Andreucci JJ, Quinn ZA, Wrana JL et al. Post-translational control of the MEF2A transcriptional regulatory protein. Nucleic Acids Res 1999; 27: 2646-2654

34. Vega RB, Harrison BC, Meadows E, Roberts CR, Papst PJ, Olson EN et al. Protein kinases $\mathrm{C}$ and $\mathrm{D}$ mediate agonist-dependent cardiac hypertrophy through nuclear export of histone deacetylase 5. Mol Cell Biol 2004; 24: 8374-8385.

35. Chen Y, Lewis W, Diwan A, EH-Y Cheng, Matkovich SJ, Dorn GW. Dual autonomous mitochondrial cell death pathways are activated by Nix/BNip3L and induce cardiomyopathy. Proc Natl Acad Sci USA 2010; 107: 9035-9042.

36. Schweers RL, Zhang J, Randall MS, Loyd MR, Li W, Dorsey FC et al. NIX is required for programmed mitochondrial clearance during reticulocyte maturation. Proc Natl Acad Sci USA 2007; 104: 19500-19505.
37. Liu N, Bezprozvannaya S, Williams AH, Qi X, Richardson JA, Bassel-Duby R et al. microRNA-133a regulates cardiomyocyte proliferation and suppresses smooth muscle gene expression in the heart. Genes Dev 2008; 22: 3242-3254.

38. Matkovich SJ, Wang W, Tu Y, Eschenbacher WH, Dorn LE, Condorelli G et al. MicroRNA-133a protects against myocardial fibrosis and modulates electrical repolarization without affecting hypertrophy in pressure-overloaded adult hearts. Circ Res 2010; 106: 166-175.

39. Yussman MG, Toyokawa T, Odley A, Lynch RA, Wu G, Colbert MC et al. Mitochondrial death protein Nix is induced in cardiac hypertrophy and triggers apoptotic cardiomyopathy. Nat Med 2002; 8: 725-730.

40. Carè A, Catalucci D, Felicetti F, Bonci D, Addario A, Gallo $P$ et al. MicroRNA-133 controls cardiac hypertrophy. Nat Med 2007; 13: 613-618.

41. Zhang W, Morris QD, Chang R, Shai O, Bakowski MA, Mitsakakis $\mathrm{N}$ et al. The functional landscape of mouse gene expression. J Biol 2004; 3: 21

42. Mcdermott JC, Cardoso MC, Yu YT, Andres V, Leifer D, Krainc D et al. hMEF2C gene encodes skeletal muscle- and brain-specific transcription factors. Mol Cell Biol 1993; 13: 2564-2577.

43. Pagiatakis C, Gordon JW, Ehyai S, Mcdermott JC. A novel RhoA/ROCK-CPI-17-MEF2C signaling pathway regulates vascular smooth muscle cell gene expression. $J$ Biol Chem 2012; 287: 8361-8370.

44. Chiang HR, Schoenfeld LW, Ruby JG, Auyeung VC, Spies N, Baek D et al. Mammalian microRNAs: experimental evaluation of novel and previously annotated genes. Genes Dev 2010; 24: 992-1009.

45. Medjkane S, Perez-Sanchez C, Gaggioli C, Sahai E, Treisman R. Myocardin-related transcription factors and SRF are required for cytoskeletal dynamics and experimental metastasis. Nat Cell Biol 2009; 11: 257-268.

46. Fei P, Wang W, Kim S-H, Wang S, Burns TF, Sax JK et al. Bnip3L is induced by p53 under hypoxia, and its knockdown promotes tumor growth. Cancer Cell 2004; 6: 597-609.

47. Wang NS. Transient expression of wild-type or mitochondrially targeted Bcl-2 induces apoptosis, whereas transient expression of endoplasmic reticulum-targeted Bcl-2 is protective against Bax-induced cell death. J Biol Chem 2001; 276: 44117-44128.

48. Gosens R, Stelmack GL, Dueck G, Mcneill KD, Yamasaki A, Gerthoffer WT et al. Role of caveolin-1 in p42/p44 MAP kinase activation and proliferation of human airway smooth muscle. Am J Physiol Lung Cell Mol Physiol 2006; 291: L523-L534.

49. Chavez JA, Summers SA. Characterizing the effects of saturated fatty acids on insulin signaling and ceramide and diacylglycerol accumulation in 3T3-L1 adipocytes and $\mathrm{C} 2 \mathrm{C} 12$ myotubes. Arch Biochem Biophys 2003; 419: 101-109.

50. Dolinsky VW, Rueda-Clausen CF, Morton JS, Davidge ST, Dyck JRB. Continued postnatal administration of resveratrol prevents diet-induced metabolic syndrome in rat offspring born growth restricted. Diabetes 2011; 60: 2274-2284.

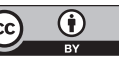

Cell Death and Disease is an open-access journal published by Nature Publishing Group. This work is licensed under a Creative Commons Attribution 4.0 International License. The images or other third party material in this article are included in the article's Creative Commons license, unless indicated otherwise in the credit line; if the material is not included under the Creative Commons license, users will need to obtain permission from the license holder to reproduce the material. To view a copy of this license, visit http://creativecommons.org/licenses/by/4.0/ 